\title{
Yaşlanmanın Coğrafyaları: Coğrafi Gerontolojide İlerleme, Tartışmalar ve Araştırma Gündemi
}

\author{
The Geographies of ageing: Progress, debates and research agenda in \\ geographical gerontology
}

Ertuğrul Murat Özgür*a

\begin{tabular}{|c|c|}
\hline Makale Bilgisi & $\ddot{O} z$ \\
\hline $\begin{array}{l}\text { DOI: } \\
10.33688 / \text { aucbd.512325 }\end{array}$ & \multirow{3}{*}{ 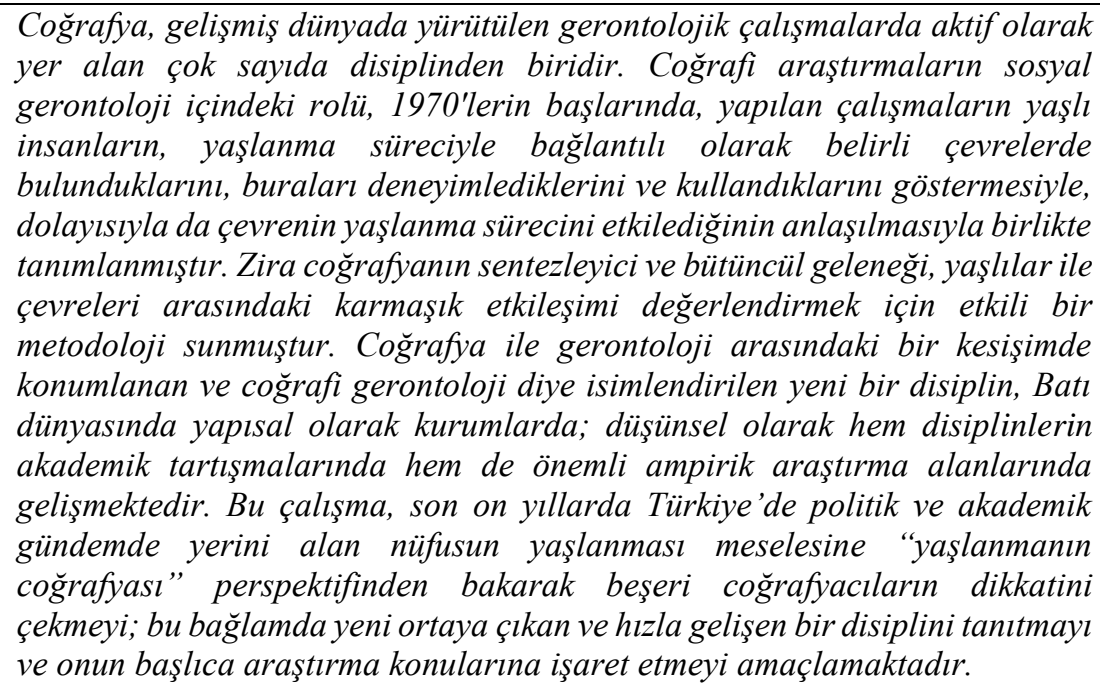 } \\
\hline $\begin{array}{l}\text { Makale Geçmişi: } \\
\text { Geliş: } 13.01 .2019 \\
\text { Kabul: } 26.03 .2019\end{array}$ & \\
\hline $\begin{array}{l}\text { Anahtar Kelimeler: } \\
\text { Yaşlanmanın Coğrafyaları } \\
\text { Coğrafi Gerontoloji } \\
\text { Nüfus Yaşlanması } \\
\text { Yerinde Yaşlanma } \\
\text { Yer/Mekân }\end{array}$ & \\
\hline Arti & bstract \\
\hline $\begin{array}{l}\text { DOI: } \\
\text { 10.33688/aucbd.512325 }\end{array}$ & \multirow{3}{*}{$\begin{array}{l}\text { Geography is one of the many disciplines actively involved in studies } \\
\text { conducted in the developing world. The role of geographical research in } \\
\text { social gerontology was first described when the studies conducted in early } \\
1970 \text { 's showed that elders presented themselves in a certain environment in } \\
\text { relation to the aging process, that they experienced and used those } \\
\text { environment and thus understanding that the aging process of the environment } \\
\text { was affected by it, because the synthesizing and holistic tradition of geography } \\
\text { represents an effective methodology to evaluate the complex interaction } \\
\text { between elders and their environment. A new discipline, called geographical } \\
\text { gerontology, positioned at an intersection between geography and } \\
\text { gerontology, has been developing structurally in institutions of the western } \\
\text { world and intellectually, both in the academic debates of disciplines and in } \\
\text { key empirical research areas. This study aims to grab attention of human } \\
\text { geographers by handling the aging population issue that has taken its place } \\
\text { in political and academic agenda of Turkey in last decades from the } \\
\text { geography of aging perspective and to introduce a newly emerging and } \\
\text { rapidly developing discipline and point to its main research areas in this } \\
\text { context. }\end{array}$} \\
\hline $\begin{array}{l}\text { Article History: } \\
\text { Received: 13.01.2019 } \\
\text { Accepted: 26.03.2019 }\end{array}$ & \\
\hline $\begin{array}{l}\text { Keywords: } \\
\text { Geographies of Aging } \\
\text { Geographical Gerontolo } \\
\text { Population Aging } \\
\text { Aging in Place } \\
\text { Place/space }\end{array}$ & \\
\hline
\end{tabular}

\footnotetext{
*Sorumlu Yazar/Corresponding Author: ozgur@ankara.edu.tr.

a Ankara Üniversitesi, Dil ve Tarih-Coğrafya Fakültesi, Coğrafya Bölümü, Ankara, Türkiye, https://orcid.org/0000-0002-21467721
} 


\section{Giriş}

\subsection{Demografik ve Sosyal Bir Gerçeklik Olarak Yaşlanma}

Bazen demografik yaşlanma olarak da isimlendirilen nüfus yaşlanması, günümüzde küresel bir olgudur. Teknik olarak, yaş ortalaması yükselen herhangi bir nüfusun yaşlandığı söylenebilir, fakat genellikle terim, 60 veya 65 yaşlarındaki kişilerin oranındaki artışa referansla daha spesifik olarak kullanılır (McCracken ve Phillips, 2005). Nüfusun yaşlanması, bir nüfusun yaş yapısının değişerek, o nüfustaki çocukların ve gençlerin payının azalması ve yaşlı insanların payının göreceli olarak artması sürecidir. Bu süreç, doğurganlıktaki düşüş ve yaşam beklentisinin yükselmesiyle yakından ilişkili olarak dünya çapında demografik yapıyı değiştiren bir olgu olarak kabul edilmektedir (Kinsella ve Velkoff, 2001; Lutz vd., 2008a ve 2008b; McCracken ve Phillips, 2005; United Nations-UN, 2007a ve 2007b). Başka bir deyişle küresel nüfus yaşlanması, doğurganlık ve ölümlülüğün yüksek düzeylerden düşük düzeylere gerilediği demografik geçiş süreciyle bağlantılı görülmekte ve dünya nüfusunun yaş yapısı, yaşlı nüfus lehine yeniden şekillenmektedir. Bu süreç, demografik geçişin erken evrelerindeki ülkelerde (örn. Sahraaltı Afrika'da), durağan ya da düşen doğurganlığın, ölümlülük düşüşüyle birleşerek artan nüfus içinde yaşlıların sayısını arttırmak suretiyle işlerken; demografik ve epidemiyolojik geçişin son evrelerindeki ülkelerde (örn. Kuzey Amerika ve Avrupa'da) düşük doğurganlık, yaşlıların sayı ve oranlarını nispeten durağan veya azalan nüfus içinde arttırmak suretiyle azalan veya sabit haldeki ölümlülükle birleşmektedir (Kinsella ve Phillips, 2005). Senaryo veya yer, ne olursa olsun, sonuç daha yaşlı insanlardan oluşan toplumlardır (Andrews vd., 2009).

Dünya genelinde toplam doğurganlık hızı (TDH) düşmektedir. Nitekim 20.yüzyıl ortalarında kadın başına 5 çocuk olan TDH, yeni yüzyılın başında 2.7 çocuğa gerilemiştir ve bu değerin 2050'de ise 2.1'e inmesi beklenmektedir. Zaten şimdi bile gelişmiş ülkelerdeki doğurganlık, nüfusun yenilenme düzeyinin (kadın başına 2.1 çocuk) altına inmiştir ki 19 ülkede doğurganlık, kadın başına 1.3 çocuktan daha azdır. Gelişmekte olan ülkelerdeki doğurganlık düşüşü ise doğurganlık geçişine girişteki geçikmeye bağlı olarak daha geç başlamış olmasına rağmen hızla devam etmektedir (UN, 2002a). Yaşlı nüfusun miktarındaki ve oranındaki artış, aynı zamanda nüfusun hayatta kalma olasılığının yükselmesiyle de ilişkilidir. Küresel olarak 2015 yllında doğuşta yaşam beklentisi her iki cins için 71 yıldır ve bu süre 1955 yılından bu yana yaklaşık 24 yıl artmıştır. Gelişmiş ülkelerde (78.4 yıl) artış 13.6 yıl, az gelişmiş ülkelerde (70.5 y1l) 28 yıl, geri kalmış ülkelerde (62.7 yıl) 26.5 yıl olmuştur (UN, 2017).

Nüfus konferansları ve ilgili literatürde nüfusun yaşlanması, büyük bir görüş birliğiyle yaygın ve bütün dünya ülkelerini yakından ilgilendiren bir süreç olarak kabul edilmektedir (Choi, 2009; Harford, 2009; UN, 2002b ve 2012; Wisensale, 2003). Önceleri gelişmiş ülkeler tarafından deneyimlenen ve daha yavaş işleyen yaşlanma sürecinin, yeni yüzyılda tüm dünyayı etkisi altına aldığı ve gelişmekte olan ülkelerin çoğunda birkaç on yıl içinde ciddi bir baskı oluşturmaya başlayacağı düşünülmektedir (Kinsella ve Phillips, 2005, Peng, 2008). Bu nedenle nüfus yaşlanması, ekonomileri ve toplumları dönüştüren çok önemli bir küresel eğilim olarak görülmektedir (UN, 2012).

Araştırmacılar arasında nüfus yaşlanmasının kalıcı ve devamlı bir olay olduğuna ve yaşlı nüfusun düzenli olarak arttığına ilişkin de fikir birliği vardır. Bu bağlamda, tüm dünyada yaşlıların (60 ve üzeri yaşlar) sayısı, 1950-2000 yı1ları arasında 205 milyondan 606 milyona yükselerek üçe katlanmıştır. Dünyada 2017 yılında, tahmini olarak 962 milyon yaşlı yetişkin vardı ve bu insanlar, küresel nüfusunun \% 13'ünü oluşturuyordu. Günümüzde yılda yaklaşık yüzde 3 hızla büyüyen yaşlı 
nüfus grubunun 21. yüzyılın ilk yarısındaki artışının yüzyıl başına göre üç kattan daha fazla olacağı sanılmaktadır. Son on yıllarda doğmuş olan nesillerin büyüklüğü göz önünde bulundurulduğunda, önümüzdeki birkaç on yıl içinde, yaşlı nüfusun daha da artması neredeyse kaçınılmaz görülmektedir (UN, 2017). Bu sayede, 1950 'de $\% 8$ ve 2007 'de \%11 olan dünya yaşlı nüfus oranlarının 2050 yılında \%21'ye erişmesi beklenmektedir (UN, 2007a). Dünyadaki yaşlı kişilerin sayısının 21. yüzyıl ortasında 2.1 milyara ve yüzyılın sonunda ise 3.1 milyara yükseleceği tahmin edilmektedir.

Yapılan araştırmalar nüfusun yaşlanmasının geçmişte görülmemiş ve insanlık tarihinde eşi benzeri olmayan bir süreç olduğuna işaret etmektedir. Bu süreçte yaşlı nüfus oranlarındaki artışa; çocuk nüfus (15 yaş altı) oranlarındaki azalma ve çalışma çağındaki nüfusun (15-59 yaşlar) düşüşü eşlik etmektedir. Küresel ölçekte, yaşlı nüfus miktarının bu yüzyıl ortalarında çocuk sayısını geçeceği tahmin edilmektedir. Çocuk sayısı 1998 yılında yaşlı nüfusun altına düşmüş olan gelişmiş ülkelerde, nüfus yaşlanmasının daha da ileri aşamalara ulaşması beklenmektedir (UN, 2007a). Bu bağlamda 21. yüzyıl başında gelişmiş ülkelerde \%20 olan yaşlı insanların oranının yüzyılın ortalarında \%30-35 düzeyine yükseleceği öngörülmektedir (UN, 2002a; Wisensale, 2006). Az gelişmiş ülkelerde yaşlı nüfus oranlarının 21.yüzyıl başındaki \%7-8'lik düzeyinden yüzyıl ortasında \%20'ye yaklaşması; geri kalmış ülkelerde ise bu oranların aynı dönemde ikiye katlanarak \%5 düzeyinden $\% 10$ 'a yükselmesi beklenmektedir (UN, 2002a).

Nüfusun yaşlanması ve yaşlı nüfusla ilgili meseleler, özellikle yaşlıların toplumla bütünleşmesi, işlevselliğinin artması ve yaşam kalitesinin yükseltilmesi konuları, küresel ölçekte içinde bulunduğumuz yüzyılın önemli demografik ve sosyal olgularından biri olarak kabul edilmekte ve dünya gündeminin ilk sıralarında yer almaktadır (Devlet Planlama Teşkilatı-DPT, 2007). Nüfus yaşlanmasının ekonomik alanda; büyüme, tasarruf, yatırım, tüketim, işgücü piyasası, emeklilik fonları, vergilendirme ve nesiller arası transferler üzerinde etkileri olacağı sanılmaktadır (UN, 2007a). Yaşlanma olgusunun sosyal kapsamda; aile kompozisyonu ve yaşam düzenlemelerine, konut talebine, göç eğilimlerine, epidemiyolojiye ve sağlık hizmeti gereksinimine etkide bulunabileceği düşünülmektedir (Harford, 2009). Politik alanda ise nüfusun yaşlanması; seçim desenlerini ve siyasi temsilleri şekillendirecek gibi görünmektedir (Lutz vd., 2008a).

Son y1llarda Türkiye nüfusunda da yaşlanma eğilimi gözlenmekte ve ülkenin ulusal yaş yapısında ciddi değişimler yaşanmaktadır (Behar, 2006; Eryurt, 2014; TÜİK, 2015). Türkiye toplumunun artık yaşlı bir toplum olduğu ve Türkiye'nin dünyanın çok hızlı yaşlanan ve yaşlanma sürecini 15-20 y1lda tamamlayacak ülkelerinden birisi olarak kabul edilmektedir (Arun, 2013). Hatta bu yüzyıl içinde Türkiye için en önemli risklerden birinin zenginleş(e)meden yaşlanma olacağına işaret edilmektedir (Arun, 2018a). Türkiye'nin 1950'de \% 6 kadar olan 60 yaş üzerindeki nüfusun oranı, 2000'de \% 8.4'e ulaşmış, 2050 ise \% 23'e erişeceği tahmin edilmektedir. Bu, ülkenin 60 ve üzeri yaşlardaki nüfusunun 1950 'de 1.24 milyon ve 2000 yılında 5.7 milyon olduğu ve nihayet 2050 yılında 23 milyona yaklaşacağı anlamına gelmektedir.

Türkiye İstatistik Kurumu'nun (TÜIK) 2017 y1lı Adrese Dayalı Nüfus Kayıt Sistemi veri tabanına göre; 10.27 milyon, 60 yaş üstü ve 1.4 milyonu aşan miktarda da 80 yaş üstü nüfus bulunmaktadır. Her iki yaşlı nüfus grubunun toplam ülke nüfusu içindeki yüzdeleri sırasıyla $\% 12.7$ ve 
\% 1.7'dir. Böylece Türkiye nüfusu, genç nüfus yapısından çıkarak yaşlı nüfus yapısına geçiş yapmak suretiyle yapısal bir değişim yaşamaktadır (Koç vd., 2010).

Türkiye'de bir yandan doğurganlık hızları düşerken diğer yandan doğuşta yaşam beklentisi yükselmektedir (Koç, 2014). Nitekim 1960'ların sonlarına kadar kadın başına 5-6 çocuk düşecek biçimde seyreden TDH değerleri (örn. 1950-1955 dönemindeki kadın başına 6.69 çocuk), 1970’lerden itibaren hızla düşerek, günümüzde nüfusun kendini yenileme düzeyine gerilemiştir (örn. 2010-2015 döneminde kadın başına 2.12 çocuk). Doğuşta yaşam beklentisi ise 1950-1955 döneminde 41.0 yıl olduğu halde; 2010-2015 döneminde 74.8 y1la yükselmiştir (UN, 2017).

Birçok ülkede yayınlanan politik belgelerin (UN, 2002b ve 2004; World Health OrganizationWHO, 2007 ve 2017) ve akademik çalışmaların bize sıklıkla hatırlattığı ve muhtemelen toplumların yavaş da olsa farkına varmaya başladığı gibi dünya ve Türkiye nüfusları gittikçe yaşlanmaktadır ve bu süreç, yirmi birinci yüzyılın baskın sosyo-demografik eğilimlerinden biri olmaya adaydır. Dünya çapında bireyler, hane halkları, topluluklar, örgütler, işletmeler, endüstriler, hükümetler ve sivil toplum, daha önce görülmemiş sayıdaki yaşlı insanın firsatları ve zorlukları ile karşı karşıyadır (Skinner vd., 2018). Yaşlanan bir dünya, sağlik ve sosyal hizmet sistemleri, refah sistemleri ve daha genel olarak hükümetler üzerinde baskı uygulamaktadır (Andrews vd., 2009). Her ülke, sahip olduğu yaşlanma düzeyine bağlı şekilde, çoğu kere sınırlı kaynaklarıyla artan taleplerle, sosyal beklentilerle ve teknolojik yeniliklerle baş etmek zorunda kalmaktadır. Yaşlanan dünya, sadece zorlukların nasıl karşılanması gerektiğine ilişkin alternatif görüşler oluşturmak açısından değil, aynı zamanda politik bir araç olduğu için de tartışma konusudur. Gerçekten ne tür iyileştirmeler yapılırsa yapılsın yaşlılık gelecekte hem devlet kurumları hem de bu süreci yaşayanlar ve yakınları için bir zorluk olarak kalmayı sürdürecektir. $\mathrm{Bu}$ yüzden yaşlanmanın nerede ve farklı yerlerdeki farklı insanlar tarafından nasıl yaşandığını ve toplumları, ekonomileri ve çevreleri her düzeyde nasıl dönüştürdüğünü anlamak, araştırmaların, politika ve programların geliştirilmesi için çok önemli hale gelmiştir. Bu bağlamdaki coğrafi sorular, gerontoloji (yaşl1lık bilimi) için yeni olmasa da küresel ekonomik, çevresel ve teknolojik değişim çağında, nüfusun yaşlanmasının aileler, sağlık sistemleri, kamu maliyesi vb. konular üzerindeki etkileri, onları her zamankinden daha da fazla dikkate değer kılmaktadır (Skinner vd., 2018).

\subsection{Akademik Bir İlgi Alanı Olarak Yaşlanma}

Son otuz yılda beşeri coğrafya, onu sosyal bilimlerin dinamik, yenilikçi ve etkili bir disiplinine dönüştüren derin bir kavramsal ve metodolojik yeniden doğuş yaşamıştır. Çok az analitik içerikle önemsiz, tamamen ampirik bir alan olarak olumsuz bir imajla uzun süredir başa çıkmaya çalışan disiplin, diğer alanlardan fikir ithal eden bir alan olmaktan fikir ihraç eden bir alana doğru kararlı bir şekilde ilerlemiş ve coğrafyacılar, gittikçe daha fazla, beşeri ve diğer sosyal bilimlerin üyesi akademisyenler tarafından okunmaya başlanmıştır (Warf ve Arias, 2009). Coğrafyadaki yeniden doğuşun bir sonucu olarak, diğer disiplinler kendi araştırma alanları için önemli bir boyut olarak mekân/yer ile gittikçe daha fazla ilgilenmektedir. Böylece edebiyat ve kültürel çalışmalar, sosyoloji, siyaset bilimi, antropoloji, felsefe, tarih ve sanat tarihi alanlarındaki güncel çalışmalar, yönelimlerinde gittikçe daha fazla mekânsal/yersel hale gelmektedir. Sosyal ve beşeri bilimlerin düşünce yapısında mekânsal/yersel bir dönüşü (spatial/placial turn) ifade eden bu olgu, coğrafya disiplininin çok ötesine yayılan ve bakış açısında çığır açan bir paradigma değişikliğidir (Pugh vd., 2009). Mekânsal/coğrafi ve zamansal/tarihi tasavvurların daha yaratıcı ve eleştirel olarak dengelenme girişimi olarak mekânsal dönüşün, 21. 
yüzyılın önemli entelektüel ve politik gelişmelerinden biri olma potansiyeline sahip olduğu belirtilmektedir (Soja, 2009: 12).

Coğrafya, gelişmiş dünyada yürütülen yaşlanma çalışmalarda aktif olarak yer alan çok sayıda disiplinden biridir. Coğrafi araştırmaların sosyal gerontoloji içindeki rolü, 1970'lerin başlarında, yapılan çalışmaların yaşı insanların, yaşlanma süreciyle belirgin bir şekilde bağlantılı olarak belirli çevrelerde bulunduklarını, buraları deneyimlediklerini ve kullandıklarını göstermesiyle birlikte çevrenin yaşlanma sürecini etkilediğinin anlaşılmasıyla kabul görmüştür (Sylvestre, 1999). Zira coğrafyanın sentezleyici ve bütüncül geleneği, yaşlı insanlar ile çevreleri arasındaki karmaşık etkileşimi değerlendirmek için araştırmacılara etkili bir metodoloji sunmuştur. Açıkçası coğrafi olmayan bir perspektiften, yaşlı insanlara ilişkin yapılan araştırmaların odakları, genellikle araştırmanın nerede yapıldığı göz önüne alınmadığı için birbirine çok benzemektedir. Oysa yaşlı insanların yaşadığı coğrafya, bu konunun ele alınmasında analitik olarak büyük önem arz etmektedir. Nitekim (insan bedeninden küresele) coğrafi ölçeğe bağlı olarak yaşlı insanların, onların ailelerinin, arkadaşlarının, gönüllülerin, hizmet sağlayıcıların ve karar vericilerin sorunları ve tepkileri çok farklı bir şekilde, fakat diğer coğrafi, demografik, ekonomik ve politik ölçeklere, eğilimlere ve politikalara bağlı olarak kendini göstermektedir (Rosenberg ve Wilson, 2018). Her ne kadar sosyoloji, demografi ve çevre psikolojisi gibi disiplinlerde mekânsal perspektif eskiden beri kullanılıyorsa da epidemiyoloji, sosyal tıp (1) ve halk sağlığında olduğu gibi bazılarında mekân/yer, yeni yeni ilgi görmeye başlamış ya da keşfedilmiştir (Diez-Roux, 1998 ve 2002). Bu ilgi ve keşif, büyük ölçüde değişik disiplinlerde yaşanan mekânsal dönüşle ilişkilidir.

Coğrafya ile gerontoloji arasındaki bir kesişimde konumlanan ve coğrafi gerontoloji (2) (geographical gerontology) diye isimlendirilen yeni bir disiplin, yapısal olarak kurumlarda; düşünsel olarak hem disiplinlerin akademik tartışmalarında hem de önemli ampirik araştırmalarda gelişmektedir. $\mathrm{Bu}$ güncel araştırma alanı, beşeri coğrafyada uzun soluklu bir disiplin geleneğinin ve sosyal gerontolojide de daha yakın zamanlarda gözlenen mekânsal dönüşün izdüşümünde yaşlanmanın coğrafyaları adı altında ortak bir ilgi alanı yaratmıştır (Skinner vd., 2018).

Türkiye'de coğrafyacıların sosyo-demografik bir mesele olarak yaşlanma konusuna ilgisi yakın yıllarda artış eğiliminde olsa da yapılan çalışmaların sayıca az olduğu saptanmaktadır (bkz. Şekil. 1). Bu konudaki ilk çalışma, Emiroğlu'nun, (1988) ulusal ölçekte yaşlı nüfus artış1 ve coğrafi dağılımına odaklanan makalesidir. İlk lisansüstü tez, Emiroğlu'nun makalesinden ancak 30 yıl sonra Akgül (2018) tarafından hazırlanmıştır ve araştırma, yerel ölçekte kırsal nüfusun yaşlanması ve yaşlı nüfusun sorunlarını incelemiştir. Yakar'ın (2018) Yaşlanma ve Yaşlılığa Coğrafi Bir Yaklaşım başlıklı kitap bölümü ise, yaşlanmanın coğrafyalarını ilk ele alan çalışma özelliğini taşımaktadır. Az sayıdaki beşeri coğrafyacının ilgi gösterdiği yaşlanmanın coğrafyalarına ilişkin bu güne kadar yapılan çalışmalar, yaşlı nüfusun mekânsal dağılımını (Avc1, 2014; Emiroğlu, 1988; Özgür, 2010; Şenol ve Saraçoğlu, 2012, Yakar, 2014, 2015 ve 2017); nüfusun yaş yapısını (Kurt, 2005; Özgür, 1999; Ünal, 2013; Yakar, 2012; Y1lmaz, 2016); yaşlı göçünü/hareketliliğini (Südaş, 2005, 2012; Şenol, 2016; Ünal, 2015); süreç, sorun ve araştırma alanı olarak yaşlanmayı (Avcı, 2016; Özgür, 2010, 2013 ve 2018; Yakar, 2018) ele almıştır. Yakın zamanda yapılan bir araştırmaya göre, Türkiye'de sosyal bilimler alanında son altı yılda gerçekleştirilen yaşlanma ve yaşlılık çalışmalarının sayısı 231'dir (Arun, 2018b) ki bu rakam, coğrafyacıların ürettiklerinin 10 katına karşılık gelmektedir. 


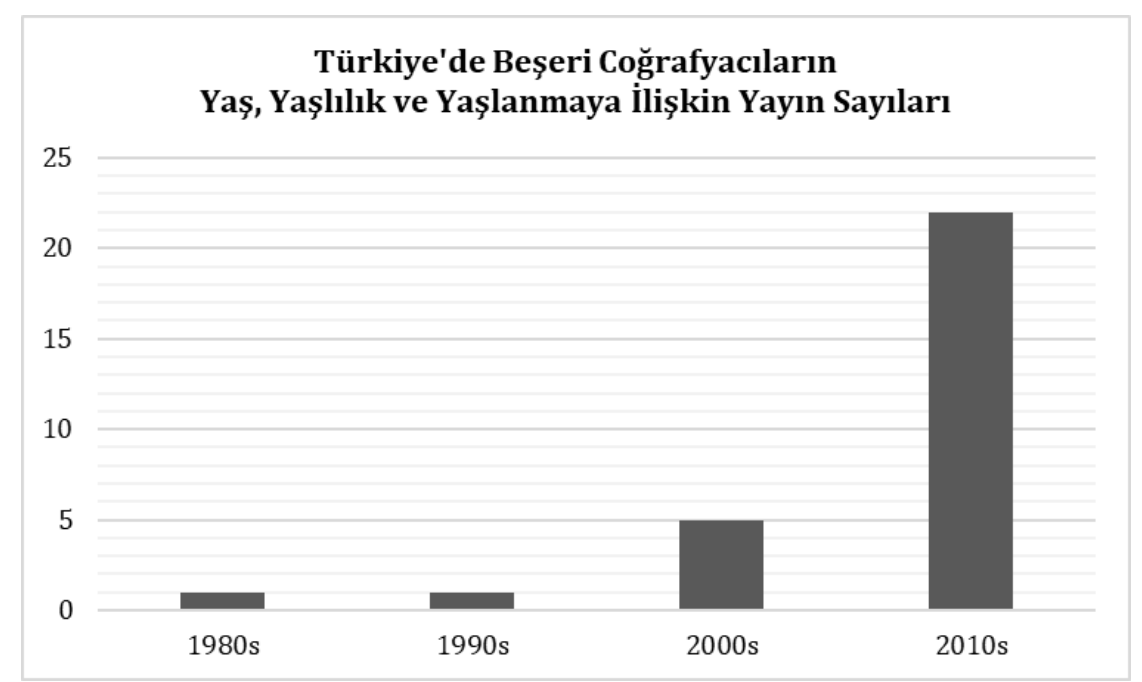

Şekil 1. Türk beşeri coğrafyacılarının yıllara göre yaş, yaşlılık ve yaşlanmaya ilişkin çalışmalarının dağılımı

Kaynak: Yazar tarafindan yapılan literatür taramasına göre hazırlanmıştır.

Gerontolog Arun tarafından yapılan bir çalışmada, yaşlanma araştırmalarının Türkiye'nin sosyo-politik ve akademik gündemine yeteri kadar giremediğine, kendi ajandasını oluşturamadığına ve oysa demografik dönüşüm sürecinde, yaşlanma ve yaşlılık meselesinin, Türkiye için risklerinin ve fırsatlarının tartışılmasının çok önemli olduğuna işaret edilmektedir (Arun, 2018b: 42-43). Arun, bu bağlamda, "yaşlanma ve yaşlılık alanında çalışan insan kaynağının kalitesinin artıılması, uzmanların yetiştirilebilmesi, araştırmacılar arasında diyaloğa dayalı bir platformun oluşturulabilmesi için nelerin yapılacağının da dikkatle değerlendirilmesi, alanda belirli bir açılım sağlayacaktır" demektedir (Arun, 2018b: 43).

Bu makale, son yıllarda Türkiye'nin toplumsal, politik ve akademik gündeminde yer bulma çabası içindeki nüfusun yaşlanması meselesine ve coğrafi gerontolojiye, bir araştırma odağı olarak Yakar'ın (2018) bıraktığı noktadan beşeri coğrafyacıların ve diğer disiplin mensuplarının daha fazla dikkatini çekmeyi; fakat aynı zamanda beşeri coğrafya ile sosyal gerontolojinin kesişim alanındaki, yani, yaşlanmanın coğrafyalarına yoğunlaşmış akademik araştırmalardaki ilerlemeyi göstermeyi ve bu alandaki güncel tartışmalara ve araştırma gündemine işaret etmeyi amaçlamaktadır.

\section{Coğrafya ile Gerontolojinin Kesişimi: Coğrafi Gerontoloji}

Araştırmalar açısından coğrafya ile gerontoloji arasındaki kesişimin anlaşılması, diğer mekânsal disiplinlerden katkıları içeren uzun ve zengin bir tarihe sahip olunduğunun kabul edilmesiyle başlamıştır (Andrews vd., 2009). Bu kesişim, 1970'lerde, sosyal psikologlar tarafından gerçekleştirilen yaşlı insanlar üzerindeki çevresel baskı unsurlarını araştıran klasik çalışmalardan (Lawton ve Simon, 1968) ve coğrafyacıların yaptığı yaşlı insanların nerede yaşadıklarına (Golant, 1972) ve günlük mekânsal yaşamlarına (Rowles, 1978) ilişkin araştırmalardan kaynağını almaktadır. Gelişmiş ülkelerde yaklaşık 40 yıldır devam eden araştırmaların ve ilerlemenin ardından, kesişim şu anda kapsamlı bir hal almıştır ve etnografik mikro-sosyoloji, çevresel psikoloji, demografi, göç çalışmaları, kentsel planlama ve mimariyi de içermektedir (Cutchin 2009; Rudzitis 1984; Wahl ve Wiesman, 2003).

Kesişim, araştırma faaliyetinin hacmi açısından uzun zamandır devam etmesine ve verimli olmasına rağmen, hep karmaşık ve tartışmalı bir alan olagelmiştir. Hem coğrafyacıların hem de 
gerontologların kesişime ilişkin ilk yaklaşımı, onun gerontolojiyi coğrafi olarak değerlendirmek üzere gerontolojinin bir alt alanı, yani gerontolojiye coğrafi bir katkıda bulunabilecek ve onun içinde coğrafi soruları ele alabilecek araştırmaların yürütüldüğü bir alan olduğudur (Warnes, 1981 ve 1990). Bu yaklaşımda gerontoloji, daha dikkat çekici ve baskındır.

1980'lerin sonlarından beri coğrafyacılar tarafından başka bir yaklaşımda, ağılıklı biçimde beşeri coğrafya ve daha özel olarak sosyal coğrafyanın özel bir alt disiplini olarak (yaşlanmanın coğrafyası başlığı altında), coğrafya ile gerontolojinin kesiştiği ifade edilmiştir (Andrews vd., 2009). Bu yaklaşım, coğrafyayı baskın disiplin kılmaktadır. Ancak bu tanımlamadaki önemli bir sorun, kesişimde çok önemli araştırmaların çoğunun coğrafya dışından üretilmiş olmasıdır. Nitekim araştırma yapan pek çok gerontologun, yaptığı şeyi coğrafya olarak kabul etmeyebileceği, bunun yerine araştırmasının yönelimi açısından coğrafi olduğunu düşünebileceği dillendirilmiştir (Andrews vd., 2007).

Yaşlanmanın coğrafyası fikrine, 2007 yılında belki de hiç beklenmeyen bir yerden, beşeri coğrafyanın kendisinden bir eleştiri gelmiştir. Beşeri coğrafyada, yaş spektrumunun kronolojik uçlarında olanlara (en yaşlı ve en genç), atfedilmiş aşırı dikkatten memnun olmayan Hopkins ve Pain (2007), yaşları, tekil demografik nesilden ziyade; nesillerarasılık (intergenerationality) ve yaşam gidişine (life course) odaklanan yaşın ilişkisel coğrafyalarını (relational geographies) savunmuştur (ilişkisel düşünce ve ilişkisellik için bkz. Andrews vd., 2013; Jones, 2009). Onlar, bu tür yaklaşımların daha fazla sayıda bireye ve onların durumuna ilişkin olarak yaşın anlamını aydınlatmaya yardımcı olabileceğini iddia etmiştir. Bu son kesişim yaklaşımı, disiplinlerin daha az ortak zemin paylaştığı anlamina gelmektedir.

Ne var ki kesişime dair sorunların birçoğuna cevap olarak ve coğrafya-gerontoloji kesişimindeki tüm araştırmaları hesaba katarak, coğrafi gerontoloji terimi kısa bir süre önce akademik literatürde yerini almıştır (Andrews vd., 2007). Bu başlık, dolaylı olarak gerontoloji üzerindeki ara yüze (yani coğrafi olarak yapılan gerontolojiye) yeniden odaklanmaktadır. Ancak bu ara yüz, iki disiplinin daha fazla bütünleştiği ve denklik ilişkisi kurduğu bir birleşimdir (Andrews vd., 2009: 1645). Yirmi birinci yüzyılın başlarında, her iki disiplinin de eleştirel-kültürel dönüşlerden etkilendiği ve geçmişte hiç olmadığı kadar teorik, metodolojik ve ampirik açıdan daha fazla ortak yönü olduğu ortaya çıkmıştır (Kontos, 2005; Kearns ve Andrews, 2005). Coğrafi gerontoloji, mekan, yer ve yaşlanma arasındaki ilişkilere ilişkin kuramları, kavramları ve ampirik bilgileri birlikte geliştirmek için uygun bir yer olarak önerilmiştir (Andrews vd., 2007). Sonuç olarak coğrafi gerontoloji, coğrafyacılar, gerontologlar ve sağlık ve sosyal bilimlerden gelen müttefik bilim insanları tarafından gerçekleştirilen yaşlanma, yaşlılık ve yaşlı nüfus çalışmalarına coğrafi perspektiflerin, kavramların ve yaklaşımların uygulanmasını sağlayan büyüyen bir disiplinlerarası akademik alana dönüşmüştür (Skinner vd., 2018).

Yaşlanma konusunu araştıran coğrafyacılar, günümüzde, yaşlanmanın coğrafyaları şemsiyesi altında doğrudan kendi disiplinleri içinde ve aynı zamanda hemşirelik, sosyal hizmetler, planlama ve çok çeşitli sosyal bilimler ve sağlık bilimleri de dâhil olmak üzere diğer disiplinlerden gerontologların coğrafi yönelimli çalışmalarını içeren ve coğrafi gerontoloji olarak anılan interdisipliner bir alanda konumlanmaktadır (Andrews vd., 2009).

Cutchin (2009), yaşlanmanın coğrafi boyutlarının araştırılmasının, hiçbir zaman tam potansiyeline ulaşamadığını ve bunun nedeninin, belki de daha başlangıçta coğrafi analizlerin 
gerontolojide sağlam bir yer bulamaması olduğunu belirtmektedir. Yaşlanmanın coğrafyası yıllar içinde, Graham Rowles, Stephen Golant, Anthony Warnes, Glenda Laws, Sarah Harper, Mark Rosenberg ve onların izinden giden az sayıdaki araştırmacının (örneğin Gavin Andrews gibi) katkılarıyla gelişme göstermiştir (Cutchin, 2009). Disiplinin içinde ve dışında, bu araştırma alanının gelişmesinin altında yatan temel etmenin, yaşlı insanlar ile yaşlılığın ve yaşlanmanın meydana geldiği ve yaşlılar sayesinde oluşan mekânlar ve yerler arasındaki dönüşümsel (reflexive), etkileşimsel (transactional) ve karşıllklı ilişkiler için uzun süredir var olan ve gittikçe artan bir değer kazanımı olduğu düşünülmektedir (Skinner vd., 2015: 778).

1940'ların sonlarında resmi bir kimlik kazanmasından bu yana gerontoloji içinde yaşlı nüfusların coğrafi yönlerine (örn. dağılımlar, hareketler, ortamlar, vb.) açık şekilde atıfta bulunulmasına ve son yarım yüzyılda nüfus coğrafyasının bir alt disiplin olarak ortaya çıkmasına rağmen yaşlanma çalışmalarına beşeri coğrafyacıların yaptığı ilk katkılar, 1970'li yıllara kadar görülmemiştir. Disiplindeki geniş çaplı değişimlerle birlikte, Anglo-Sakson coğrafyacılar tarafindan on yıllık öncü çalışmalardan başlayarak (Rowles, 1978, 1986; Warnes, 1981, 1982, 1990; Golant, 1984a, 1984b) coğrafyadan gerontolojiye katkılar, pozitivist, hümanist ve daha yakın zamanlarda eleştirel sosyal teori ve kültürel yönelimlerden kaynağını almıştır (Andrews vd., 2007).

Coğrafi gerontoloji, beşeri coğrafya ile sosyal gerontolojinin bazı alt alanlarının kesişiminde yaşlanmanın coğrafyaları bağlamında ürünlerini vermektedir. İki disiplinden beşeri coğrafya altında sağlı coğrafyası, nüfus coğrafyası ve sosyal coğrafya başta olmak üzere eleştirel coğrafya, kültürel coğrafya ve kentsel coğrafya, oluşumuna tanık olunan coğrafi gerontolojiye önemli katkılar sunarken; sosyal gerontoloji kanadından eleştirel gerontoloji, kültürel gerontoloji, çevresel gerontoloji, sağlık hizmetleri ve sosyal hizmetler, sosyal yaşlanma teorileri ve yaşam gidişi çalışmaları, coğrafi gerontolojiye önemli ölçüde destek veren alt alanlardır (Şekil 2).

Araştırmaların odağında, genel anlamda, demografik yaşlanmanın mekânsal örüntülerinden (yaşlı nüfusun dağılımı, hareketi ve göçü), sağlık hizmetleri ve altyapısına; yaşlı insanların yaşam düzenlemeleri ve ortamlarına; yaşlanma, sağlık, bakım ve refahın yere-gömülü deneyimlerine ve daha yakın zamanlarda bu alandaki deneyimlerin vücut bulmasına/somutlaşmasına (embodiment) ve temsillerine kadar çok çeşitli konular bulunmaktadır (Şekil 2).

Batılı beşeri coğrafyacıların yaşlanmanın coğrafyaları üzerine yaptıkları araştırmalarının zamanla gerontolojik bilgi birikiminin gelişimine katkıda bulunduğuna dair bir fikir birliği vardır. Disiplin içinde yaşlanma araştırmaları için gündem, çoğunlukla coğrafi kavramların, yaklaşımların ve ampirik çalışmaların katkısına ilişkin bilgisizliğin giderilmesiyle ilgili olarak gelişmiştir. Ancak disiplinin hem içinde hem de gittikçe daha fazla olarak dışında, coğrafi gerontoloji alanı için temel öncelikleri ve doğrultuları ortaya koyan, birbirine bağlı ve eleştirel bir canlı gündeme doğru yol alınmıştır (bkz. Harper ve Laws, 1995; Andrews vd., 2007). Aynı zamanda, disiplinle ilgili ve disiplinler arası sınırlar, araştırmalara finansman sağlayanların, yaşlanma çalışmalarında disiplinler arası işbirliklerini desteklemesi ve üniversitelerin kendi birimleri ve kurumlar arasında, özellikle sağlıkla ilgili ve sosyal alanlarda işbirlikçi araştırma modellerini teşvik etmeleri nedeniyle gittikçe daha da bulanıklaşmıştır (Andrews vd., 2009). 


\section{Coğrafi Gerontolojide Kaydedilen İlerleme}

Coğrafi gerontolojinin geçmişi, daha önce belirtildiği gibi bir dizi önemli dönüm noktasi sayılabilecek çalışmayla (Golant, 1972; Rowles, 1978; Warnes, 1982) 1970'li yılların başına kadar uzanmaktadır. Bu erken döneme ait çalışmalardan bu yana, coğrafi yaşlanma araştırmaları, hem kapsam hem de hacim açısından büyük ölçüde genişlemiştir (Andrews vd., 2007). Progress in Human Geography dergisinde, 20. yüzyılın son çeyreğinde yayınlanmış dört rapor, (Harper ve Laws, 1995; Rowles, 1986; Warnes, 1981 ve 1990) ve daha yakın zamanlarda hazırlanmış çalışmalar (Andrews \& Phillips, 2005, Andrews vd., 2007; Skinner vd., 2015) bu artan katkının belirtisi ve yaşanan tartışmaların özeti gibidir.

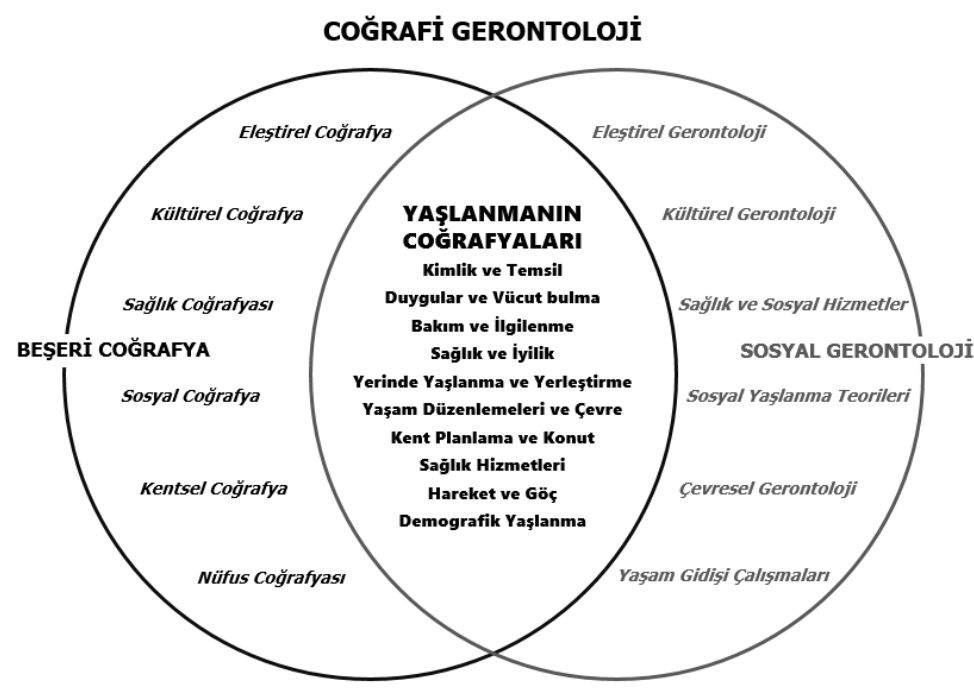

Şekil 2. Coğrafi Gerontoloji ve Yaşlanmanın Coğrafyaları Kaynak: Skinner vd., 2015: 778

Coğrafi gerontoloji için geniş bir gündem yaratan ilk çalışma, Warnes'ın (1981) nüfusun mekânsal yönlerine ve yaşlı insanların lokasyonlarına, hareketlerine ve onlarla ilişkili hizmetlere odaklanan raporudur. İkinci raporda Rowles (1986), araştırmaların genişlediğini, ancak Warnes'in orijinal gündeminin ötesine geçmediğini ileri sürmüştür. Coğrafi gerontoloji için daha tutarlı ve kapsamlı bir gündem oluşturmaya çalışan Rowles'ın asıl odağı, etkileşimsel bir bakış açısından yaşlılar ile çeşitli ölçeklerdeki çevreleri arasındaki ilişkiyi vurgulayan yaşlanma olmuştur. Bu bağlamda Rowles, araştırmacıları özellikle $e v$ ile bağlantılı olarak yerin anlamı (meaning of place) ve yer anıları (place memories) ile ilgili araştırmalar yapmaya çağırmıştır.

Üçüncü raporda Warnes (1990), alternatif bir bakış açısıyla coğrafyacıların önceliklerini ve amaçlarını, beşeri coğrafyanın kuramsal ihtiyaçlarından (örn. yerin niteliğini tartışmaktan) yaşlı insanların ihtiyaçları üzerine kaydırmaları gerektiğini savunmuştur. Warnes (1990), coğrafyacıların üzerinde yeterince durulmadığı üç meseleye dikkat çekmiştir: (a)Demografik yaşlanmanın küresel gelişimi ve etkileri, $(b)$ yaşı insanların yaşam koşullarındaki lokasyonel boyutlar ve $(c)$ çevre ile yaşlı insanlar arasındaki etkileşimin zamansal değişimi. 
Coğrafi gerontolojiye ilişkin dördüncü ilerleme raporunda Harper ve Laws (1995), Rowles'1n (1986) raporundaki düşünceleri sahiplenerek; araştırma için yeni yollar açmak üzere coğrafi gerontolojinin, beşeri coğrafyadaki kültürel dönüşten(cultural turn) teorik ve metodolojik dersleri öğrenmeye ihtiyacı olduğunu ileri sürmüştür. Onlar, yaşlanma araştırmalarıyla ilgili birçok konuyu yeniden canlandırmak ve çerçevesini çizmek, yanı sıra tartışılabilir bir sosyal yapı olarak yaşın kendisine katkı sağlamak ve dikkat çekmek için politik ekonomi, feminizm ve post-modernizm ile daha yakın ilişki kurulması gerektiğine vurgu yapmıştır (Harper ve Laws, 1995). Bu bağlamda Harper ve Laws (1995), özellikle bakımın politik ekonomisi, hizmet sunumunda devletin rolü, toplumsal cinsiyet rolleri ve stereotipler ile insanların yaşam gidişi araştırılırken; eleştirel sosyal teori ve post-modern perspektiflerin daha fazla benimsenmesi gerektiğini savunmuştur. Ayrıca onlar, beşeri coğrafyacıların coğrafi olarak yaşlanmayı birden fazla ölçekte ele alabileceğini belirtmiştir. Bu uğraşının, (a)yaşam gidişi boyunca bir süreç ve deneyimler paketi şeklinde bireysel/mikro ölçekte; (b)yaşlı insanları, onların içinde yaşadıkları topluluklara ve çevrelere (veya yerlere) bağlamanın bir aracı şeklinde, kolektif olarak/orta ölçekte ve (c)nihayet örneğin, emeklilik, emekli maaşları, sağlık ve sosyal hizmet sunumu, göç ve konutla ilgili politikalar için demografik yaşlanmanın etkilerini anlamak için bir yol olarak küresel/makro ölçekte olabileceğini savunmuştur(Skinner vd., 2015: 780). Nihayetinde onlar, coğrafyacıların ve gerontologların, bilgiyi ilerletmeye ve sosyal değişime katkı sağlamaya yönelik sorumluluk bilinci ve yaşlıların yaşamlarını zenginleştirmek isteği ile hareket eden eleştirel-politika odaklı araştırmaları sürdürmeleri gerektiğine vurgu yapmıştır.

Harper ve Laws'ın (1995) derlemesinden on yıl sonra Andrews ve Phillips (2005), aynı zamanda editörlüğünü de yaptıkları kitabın (Ageing and Place: Perspectives, Policy, Practice) içinde yer alan değerlendirme yazılarında, coğrafi gerontoloji araştırmalarında, uluslararası ve ulusal bağlamlarda yaşlıların demografik geçişlerinin ve mekânsal dağılımlarının dikkate alınmaya ve yaşlı nüfusun göç paternlerinin önemli bir odak noktası olmaya devam ettiğini, yanı sıra emekli göçünün sosyo-mekânsal eğiliminin araştırıldığını belirtmiştir. Bununla birlikte yazarlar, yapılan araştırmalarda, yaşlı nüfusun mekânsal dağılımları konusunun zaman içinde aile etkileşimlerindeki değişimlere ve bağlılıklara ve aile üyelerinin artan mekânsal bölünmelerine doğru genişletildiğini de eklemiştir.

Dahası Andrews ve Phillips, başka bir yerleşik araştırma geleneği olarak yaşl1lar için özel ve kamu sektörleri tarafından sağlanan kaynakların mekânsal tahsisinin ve kullanımının incelenmeye devam edildiğini, özellikle, ev-temelli sosyal bakım tesislerinin ve ikamet yerlerinin ulusal ve bölgesel ölçeklerdeki dağılımının, bu araştırmaların ana odak noktaları olduğunu dile getirmiştir (2005: 10-11). Bu çalışmada, başka bir araştırma dizisinin yaşlıların yerler ve mekânlar ile kişisel ve gelişen ilişkileriyle ilgili olduğu belirtilmiş; daha yeni bu araştırmaların çoğunun, yaşlıların hizmetlere erişimini etkileyen çevresel sınırlamaları göz önünde bulundurduğu, ayrıca, hem kentsel hem de kırsal yaşam çevrelerinde yaşlı insanların karşılaştığı sorunların ve yerel planlama ve daha geniş sosyal politika sonuçlarını araştırdığı; başarılı yaşlanma ve kısıtlamalar bağlamında yaşlıların yeterliliklerini etkileyen yakın çevre bileşenlerine artan düzeyde dikkat verdiği dile getirilmiştir. Daha genel olarak, çevre ve yaşlanmanın, hızla yaşlanan birçok ülkede önemli bir ulusal ve kentsel planlama meselesi olarak görülmeye başlandığının, yerinde yaşlanma kavramının karmaşık bir coğrafi süreç olarak analiz edildiğinin altı çizilmiştir (Andrews ve Phillips, 2005: 12). 
Son olarak Andrews \& Phillips'ten (2005) yine on y1l sonra Skinner, Cloutier, ve Andrews'in (2015) "Yaşlanmanın coğrafyaları: Yirmi yıllık değiş̧imden sonra ilerlemeler ve firsatlar" başlığını taşıyan yazıları, coğrafi gerontoloji araştırmalarında gelinen noktayı çok iyi resmetmektedir. $\mathrm{Bu}$ makalenin geri kalanında Skinner, Cloutier, ve Andrews'in (2015) değerlendirme makalesinden ve başka çalışmalardan (örn. Andrews vd., 2018; Diaz-Moore, 2018; Milligan ve Tarrant, 2018; Rosenberg ve Wilson, 2018; Skinner vd., 2018; Wiles, 2018) yararlanmak suretiyle coğrafi gerontolojinin güncel araştırma ve tartışma gündemini ele almaya çalışacağım.

\section{Coğrafi Gerontolojideki Güncel Tartışmalar ve Araştırma Gündemi}

Son y1llarda hem pozitivist hem de eleştirel geleneklerden gelen Kuzey Amerikalı ve Avrupalı beşeri coğrafyacılar, yaşlanma coğrafyalarındaki tartışmalara katkıda bulunmuştur (Hardill, 2009). Bazı coğrafi çalışmalar, ampirik pozitivist bir yaklaşımla, yaşlanma ve hizmet sunumunun mekânsal örüntülerini ve yaşam döngüsü perspektifinden göçü anlamaya odaklanmıştır. Bazılarıysa yaşlanmayı ve mekânı kavramsallaştırmada feminizm, post-yapısalcılık ve post-modernizm yaklaşımlarından beslenmiştir. Bu çerçevede yakın zamanlarda, özellikle sosyal ve kültürel coğrafya içinde, yaşlanmaya ilişkin ilginin kapsamı genişlemiş ve derinleşmiş; zengin kuramsal ve metodolojik çoğulculuk ve belirgin bir yaklaşım çeşitliliği ortaya çıkmıştır (Skinner vd., 2015). Aynı zamanda yaşılıların vücut bulmuş/somutlaşmış ve duygusal coğrafyaları (embodied (3) and emotional geographies) şemsiyesi altında ve gündelik gerçeklikleri düzeyinde, yaşlı bireylere duyulan ilgi artmıştır (Anderson ve Smith, 2001; Hopkins ve Pain, 2007).

\subsection{Nüfus Yaşlanması ve Yaşlı Nüfusun Dağılışları}

Nüfus yaşlanması ya da demografik yaşlanma araştırmaları, hem coğrafya hem de gerontolojide uzun süredir var olan geleneklere sahiptir. Bu çalışma alanı, her iki disiplin içinde de nüfus ve sağlık coğrafyacıları ile demograflar tarafından yaşlı nüfus üzerine yapılan ampirik ve pozitivist yaklaşımları içeren nicel araştırmalarla yönlendirilmiştir (Kinsella ve Phillips, 2005; Kinsella ve Velkoff, 2001). Nüfus coğrafyası ve demografideki gelişmelerle (bkz. Özgür, 2016) uyumlu olarak, demografik yaşlanma eğilimleri ve yaşlı nüfusların değişik coğrafi ölçeklerde (küresel, uluslararası, ulusal ve altulusal) dağılımı ve değişim paternleri ortaya koyulmakta; elde edilen görünümler, çeşitli ekonomik, çevresel, mali, sağlık ve sosyal problemlerle ve bunlara dair politikalarla ilişkilendirilmektedir. Ek olarak yakın zamanlarda coğrafi bilgi sistemleri ve mekânsal istatistik teknikleriyle yapılan analizler nüfus eğilimlerini anlamada ve haritalamada yeni analitik yollar sunmaktadır. Demografik yaşlanmanın küresel eğilimleri, çoklu analiz ölçeklerindeki faktörlerini daha iyi anlayabilmemiz için uzunlamasına (longitudinal) çalışmalar ve modellemelerle geliştirilmeye çalışılmaktadır (Andrews ve Phillips, 2005).

\subsection{Yaşlı Göçü, Hareketliliği ve Yaşlıların Akrabalarına Coğrafi Yakınlığı}

$\mathrm{Bu}$ alana, sosyoloji ve coğrafya da dâhil olmak üzere bir dizi disiplin mensubu katk1 sağlamaktadır. Yürütülen araştırmalarda, yaşlıların coğrafi hareketlerinin doğası, etkileri ve sonuçları açıklanmaya; onların akrabalarına coğrafi yakınlığı ile akrabalarla etkileşimlerinin niteliği arasındaki ilişki tanımlanmaya çalışılmıştır (örn. bkz. Glaser ve Tomassini, 2000; Glaser vd., 2004; Hank, 2007; Lin ve Rogerson, 1995; Michielin ve Mulder, 2007; Shelton ve Grundy, 2000; van der Pers vd., 2015). $\mathrm{Bu}$ araştırmalar, yaşlılar ile akrabalarının yaşadığı yerler arasındaki mesafeler fazlaysa, genellikle daha 
az etkileşim ve ilişki olduğunu göstermiştir. Bununla birlikte hem gerçek mesafenin hem de mesafenin etkilerinin yaşlıların ve onların yetişkin çocuklarının işlevsel durum ve sağlık, sosyo-ekonomik durum, toplumsal cinsiyet, medeni durum ve aile dengesi, eğitim, yaş ve istihdam durumu gibi özelliklerle birlikte sağlanan desteği etkilediği de ortaya koyulmuştur. Belki bu tarz çalışmalara yaşlılar ile yakınları arasındaki mesafenin etkilerini azaltan ulaşım ve iletişim teknolojilerindeki ilerlemenin etkilerinin anlaşılmasına yönelik olanlar da katılabilir.

Yaşlı nüfusların göç ve hareketlilik paternleri ve motivasyonları, (yaşlı göçü, emekli göçü, mevsimsel yaşlı hareketleri); zaman içinde aile etkileşimlerindeki ve bağlarındaki değişimler ve aile bireylerinin mesafeler sayesinde ayrı düşmesinin sonuçları, gittikçe daha fazla incelenmektedir (CasadoDiaz vd., 2004; Gustafson, 2000, 2001 ve 2008; King vd., 1998; King ve Newbold, 2009; Newbold, 2008; Sunil vd., 2007; Warnes, 2009; Warnes ve Williams, 2006). Yaşl1 nüfusun hareketlilik ve göçü, özellikle de son zamanlarda ulusal sınırlar içinde ve sınırların ötesine taşan emekli göçü, coğrafya ve gerontoloji için önemli ve ortak bir odak noktası olmaya devam etmektedir. İster kış mevsiminde daha sıcak iklimlere doğru yönelen ve kar kuşları(snowbirds) diye isimlendirilen grubun ya da Türkiye'de olduğu gibi yazın tatil yörelerine akan emekli yazlıkçıların seyahatleri gibi sarkaç hareketlerine ya da diğer yaşam geçişlerine odaklanılsın, isterse olanaklara, hizmetlere ya da bozulan sağlık ve azalan yetenekler nedeniyle aile üyelerine daha yakın olmak için kısa mesafeli yer değiştirmelere veya emeklilik, dulluk ve yeniden evlenme gibi yaşam gidişi koşullarına bağlı olarak hareketlere odaklanılsın; yaşlı insanların hareket paternlerine ve motivasyonlarına ilişkin geleneksel vurgu, yaşlanma çalışmalarında halen ilgi görmektedir (Skinner vd., 2015).

\subsection{Yaşlıların Yaşam Çevreleri}

Yaşlı sağlı̆̆ının tıbbi olmayan yönleri, hem coğrafyada hem de gerontolojide incelenmektedir. Bununla birlikte, yaşlı sağlığı alanındaki önemli bir eğilim, yer ve çevrenin sağlıkla ilgili etkilerini araştırma yönündedir (Andrews vd., 2007). Yaşlıların sağlık durumuna ilişkin çalışmaların tersine, yaşlanma çevreleri üzerine yapılan araştırmalar, sağlık coğrafyacılarının, çevre psikologlarının ve sosyologların gittikçe daha fazla nitel yöntemle yapılan çalışmalarını içermektedir. Bu alandaki araştırmalar, yaşı insanların ihtiyaç duydukları özel yaşam çevreleri (ev ve ikametgah alanı) ve bu çevreler içindeki etkileşimlerden; yaşlıların yaşadıkları, çalıştıkları, zaman geçirdikleri ve bakım hizmeti aldıkları farklı çevrelerin, yerlerin ve toplulukların bağlamsal yönlerine kadar çeşitli meselelerle ilgilidir (Andrews vd., 2009). Bu çalışmalar, aynı zamanda konut, mahalle, kent merkezi ya da kırsal yerleşim birimi gibi belirli yaşam çevrelerinin yaşlı insanlar için nasıl uygun ve sağlıklı çevrelere dönüştürülebileceği üzerine de odaklanmaktadır (örn. bkz. Michael vd., 2006; Phillips vd., 2005; Walter-Ginzburg vd., 2004). Bu tür araştırmalar, sosyal gerontolojik yaklaşımları, yaşlılar ile onların değişen sosyal ve fiziksel çevreleri arasındaki ilişkilerin coğrafi yorumlanmasına bağlamaktadır. Sosyal ve coğrafi gerontolojide daha fazla araştırma, toplu konut (congregate housing) (4) ve destekli yaşam veya benzeri ortak konut alanlarına yönelik hizmetlere, korunaklı yaşam yeri sektörüne de dikkatini vermektedir.

Coğrafyacılar, kırsal ve kentsel yaşl1lar için yaşlanma deneyimlerini farklı şekilde etkileyen etmenleri, kırsal ve kentsel yaşlıların sağlık, bakım ve sosyal destek ile ilgili temel farklılıklarını gözden geçirmektedir (bkz. Buffel ve Phillipson, 2018; Skinner ve Winterton, 2018). Bazı araştırmalarda yaşlı insanların toplumların sürdürülebilirliğine nasıl katkıda bulunabileceği, yaşl1-emeklilerin kırsal alan 
ekonomisi üzerinde ne tür etkilerinin olduğu gibi daha geniş sosyal bağlamlar açısından kırsal yaşam çevrelerini incelemektedir. Bir grup araştırmacı, yaşlı yetişkinlerin toplumun geri kalanıyla bütünleşmesi ile ilgili çalışmaktadır. Bazıları, yaşlıların toplumun geri kalanından ayrışması gerektiği (ve ayrılmak istediği) görüşü üzerinde durmaktadır (bkz. Rosenberg ve Everitt, 2001). Her iki disiplin, nüfus yaşlanmasını anlamak için insan-çevre ilişkilerinin önemini vurguladığı halde; coğrafyacılar geleneksel olarak yaşlı insanların yaşamlarının yerel bağlamsal ve bileşimsel boyutlarına odaklanırken, sosyal gerontologlar yaşam gidişi boyunca yaşlanmanın çevresel yönlerini vurgulamaktadır (Andrews vd., 2007).

Dünya Sağlık Örgütü tarafından 2005 yılında başlatılan ve aktif yaşlanmaya olanak sağlayan bir çevrenin varlığına ve önemine işaret eden Yaşlı Dostu Kentler ve Topluluklar (Age-friendly Cities and Communities) anlayışı da araştırmalarda ilgi toplamaktadır (WHO, 2007). Bu anlayış, yakın zamanlarda Yaşlı Dostu Çevreler (Age-friendly Environments) şeklinde geliştirilmiştir (WHO, 2017). Yaşlı dostu kent veya çevre, yaşlıların toplumda herkes gibi yaşayabilecekleri, toplumla bütünleşebilecekleri yaşanabilir bir ortamın yaratılması yönünde geliştirilmiş bir modeldir. Yaşlı dostu kent/çevre bilincinin ve pratiğinin yaşam alanlarında var olabilmesi için uygulayıcı mekanizmaların olması gerekir. Günümüzde yapılanmaları, görevleri, toplumsal sorumlulukları gereği yerel yönetimler bu süreçte ana uygulayıc1 konumundadır (Aslan, 2015: 27).

\subsection{Bakımın Coğrafyaları: Yerinde Yaşlanma ve Doğru Yerde Yaşlanma}

Yaşlanmanın coğrafyaları, yaşlanmanın gerçekleştiği mekânsal bağlamları dikkate alarak, yaşlıların mümkün olduğu kadar evde yaşamayı ve yerinde yaşlanmayı tercih ettiklerini kabul etmektedir (Skinner vd., 2015). Bakımın coğrafyaları (Geographies of care), hem verme hem de alma zorlukları ve deneyimleri de dâhil olmak üzere, savunmasız ve güçsüz yaşlılara bakım sunumunun mekânsal bağlamını değerlendirmektedir. Bu çerçevede ev, bakım hizmetlerinin verilmesi ve alınması için çok önemli bir yer olarak görülmektedir. Gerçekten de güçsüz yaşlı insanlar için ev bakımı, yerinde yaşlanma için yaşlılar ve onların ailelerinin tercihleri, kurumsallaşmayı (huzurevi gibi) azaltmaya yönelik kamu politikaları ile işlevsel ve ikametgâha dair bağımsızlığı teşvik etme niyetleri arasındaki az rastlanır bir yakınlaşmayı temsil etmektedir. Evde bakım hizmetleri, bu hedefi desteklemekte ve birçok sanayileşmiş ülkede sağlık sistemlerinin temel bir dayanağı olarak işlev görmektedir (Martin-Matthews ve Cloutier, 2018).

Yaşlı insanların yaşadığı gündelik yaşam mekânları, onlar mekânın mahkûmları haline gelene kadar kademeli olarak büzülmektedir. Hem coğrafyacıların hem de gerontologların bu konu üzerine daha fazla eğilmesi, yaşlı insanlar için gündelik deneyimler ve bakım uygulamalarında yer kavramıyla bağlantılı olduğu içindir (Milligan, 2000; Peace vd., 2006; Wiles, 2005). Bu tür çalışmalar, yaşlı insanlar ile onlara bakım verenler için yaş ilerledikçe ve savunmasızlık düzeyi arttıkça, evin ve toplumun değişen doğasını ve deneyimlerini ortaya koymakla kalmamakta, aynı zamanda özerklik ve kimlik duygusunu desteklemede ve sürdürmede bağlamın ve yer bağlılığının önemini de vurgulamaktadır. Bu noktada birbiriyle yakından ilişkili, hatta örtüşen iki kavram, yani yerinde yaşlanma ve yer bağlllı̆̆l, politik alanda ve literatürde karşımıza çıkmaktadır.

Yaşlanma, sağlık/bakım ve yer arasındaki ilişkileri inceleyen araştırmalar genellikle, Rowles'in (1983; 1993) çalışmaları üzerine inşa edilmiştir. Yerinde yaşlanma (ageing in place), yaş, gelir veya 
kapasite düzeyinden bağımsız olarak yaşlının kendi evi ve topluluğu içinde güvenli, bağımsız ve rahat bir şekilde yaşama becerisini anlatmaktadır. Golant'ın(2015) ileri sürdüğü doğru yerde yaşlanma (ageing in the right place) ise, bu kavramı kişinin kendi ihtiyaçları ve tercihlerine en uygun yerde yaşayabilme kabiliyetine genişletmektedir ki bu yer, kişinin kendi evi olabileceği gibi kendisine uygun başka bir yer de olabilir (WHO, 2015: 225).

Öte yandan yer bağ lılı̆̆ kavramı, insanların yerlerle geliştirdiği bağlara atıfta bulunmaktadır ve duygusal, bilişsel ve davranışsal üç bileşenden oluşmaktadır (Lewicka, 2008: 211). Low ve Altman, (1992) yerlerin ve nesnelerin öngörülebilir olanaklar sağlaması, formel rollerden sıyrılma firsatı, kişiye yaratıcı olma ve hayatının çeşitli yönlerini kontrol etme şansı sunmasıyla yer bağlılığının, güvenlik ve uyarılma duygusu sağlayabileceğini; bu bağlılığın kişiyi arkadaşları, partnerleri, çocukları ve akrabaları ile açık ve görünür bir şekilde ilişkilendirebileceğini belirtmektedir. Ayrıca onlar bunun insanları başkalarına sembolik olarak bağlayabileceğini ve kişinin çocukluğunu, ebeveynlerini, arkadaşlarını, atalarını ve başka şeyleri hatırlatabileceğine işaret etmektedir (Low ve Altman, 1992: 10). İnsanlar yaşlandıkça, hem nesnelere hem de yerlere gittikçe daha fazla anlam yüklemekte, duygusal olarak onlara bağlanmakta ve yer bağl1lığı daha güçlü hale gelmektedir.

\subsection{Yaşlanmanın Sağlık Coğrafyaları}

Coğrafya, yaşlanma sürecinin önemli bir unsurudur. Bir yandan yaşlanma, sağlık coğrafyalarını şekillendirilirken öte yandan da sağlık coğrafyaları yaşlanmayı şekillendirmektedir. Yaşlanmanın sağlık coğrafyaları, daha önceki sağlığı biyomedikal bir bağlamda ele alma eğiliminden, şimdi sosyal, fiziksel ve sembolik bağlamlarda yaşlanma ve sağlık hakkında daha bütüncül sosyo-ekolojik anlayışları benimsemeye yönelmiştir. İnsanlar ile onların fiziksel, sosyal ve sembolik çevreleri arasındaki ilişkiyi inceleyen sağlık coğrafyacıları, insan bedeninden bölgesel ve küresel ölçeklere kadar sağlığın, hastalığın ve sağlık için çeşitli kaynakların dağılımına ve bağlantılarına odaklanmaktadır (Wiles, 2018).

Mekân bilimi yaklaşımıyla çalışan araştırmacıların çoğu, yaşlanma ve sağlık coğrafyasına yaşlanan nüfusların küresel, bölgesel ve kentsel düzeylerdeki dağılımlarının etkilerini ölçmeye ve anlamaya odaklanmıştır (Cook ve Halsall, 2011; Moore ve Rosenberg, 2001). Araştırmacılar hastalık, teknoloji ve sosyal koşullardaki eğilimlerin farklı mekânsal ölçeklerde yaşlanmayı nasıl şekillendirdiğini ortaya koymaktadır (McCracken ve Phillips, 2005). Yaşlı insanların, yaşl1lıktaki sağlık çıktılarının ve yaşam kalitesinin dağılımlarındaki örüntüleri ve özellikle de eşitsizlikleri araştırmaktadır (Warnes, 1999). Bu tür bilgiler, yaşlılık ile ilgili bir dizi hizmet ve destek talebini gösterebilmek ve gelecekteki ihtiyaçları planlamak için yararlıdır (Rosenberg, 2014).

2000'li yıllarda hem sağlık coğrafyasında hem de gerontolojide yerin sağlık üzerindeki etkisiyle ilgili çalışmalarda ciddi bir artış olduğu gözlenmektedir (Cagney vd., 2005; Dempsey vd., 2018; Eschbach vd., 2004; Kobetz vd., 2003; Macintyre vd., 2002; Nordstrom vd., 2004). Yaşlanmanın sağl1k coğrafyalarını ilişkisel yaklaşımlarla inceleyen çalışmaların bazılarında, yaşı insanların sosyal ve fiziksel çevrelerle etkileşimlerini anlamayı amaçlanmakta; insanlar ile onların çevreleri arasındaki ilişkinin birlikte ele alınması gerektiği savunulmaktadır (Kontos, 1998; Rowles, 1978, 1986; Rubinstein, 1990; Sugihara ve Evans, 2000). Sağlıklı yaşlanmaya ve yaşlı psikolojisine ilişkin olarak önemli temalar arasına yer duygusunu ve yere bağlılığını katmak gerekmektedir. Zira araştırmalar yer ile iyi bir bağ kurmuş yaşlıların, kendilerini güvende hissetme, kontrol ve olumlu bir benlik duygusu geliştirme olasılığının yüksek olduğuna işaret etmektedir (Rowles, 1986; Rowles ve Ravdal, 2002; Rubinstein, 
1989). Bu yüzden yaşlıların yer ile kurdukları bağın(ya da bağ kuramamanın), insanların yaşlandıkça, hem nesnelere hem de yerlere yüklediği anlamların anlaşılması önemlidir. Aşinalık, duygusal bağlantılar, arkadaş ve aile ağları ve kişinin bir yere bağlanarak oluşturduğu kimlik veya geçmiş duygusu, Rowles'ın (1993) yerde olma ya da içindelik olarak ifade ettiği şeylere katkıda bulunacaktır.

Yaşlı insanların lokasyonunu ve hareketlerini anlamak, onlara yönelik hizmetler ve desteklerle ilgili olduğu için yaşlıların sağlık ve bakım coğrafyaları açısından da önemlidir (bkz. Wiles, 2018). Ancak, sağlık coğrafyası açısından bu hareketlerin, insanların yaşamlarının karmaşıklığının bir parçası olarak (Rowles ve Watkins, 1993) veya bakım-destek alışverişi ve sağlık üzerindeki etkileriyle ilgili olarak anlaşılması gerekmektedir (Smith, 1998a). Zira olumsuz yaşam olayları tarafından yönlendirilen hareketler, örneğin, depresif etkiler yaratabilmekte veya stresli olabilmektedir (Bradley ve Van Willigen, 2010). Hem yaşlıların hem de onların ailelerin coğrafi olarak yakın olmaya ilişkin aldıkları kararlar, çoğu zaman, onların etkileşimlerinin niteliği açısından önemli sonuçlara sahiptir (Smith, 1998b). Yaşlı biri ile aile üyeleri arasındaki coğrafi yakınlık, genellikle daha fazla bakım sağlanmasıyla ilişkili olarak hem bakımın süresini hem de sağlanan desteğin türünü etkilemektedir. Bununla birlikte bu durum, hem yaşlı hem de potansiyel bakım desteği verenlerin sağlık, toplumsal cinsiyet, medeni ve ebeveynlik, istihdam durumlarından etkilenmektedir (Hallman ve Joseph, 1999; Joseph ve Hallman, 1998).

Bazı sağlı coğrafyacıları, hem yaşlı insanların hem de kentsel, bölgesel ve küresel yönetişim bakış açılarından yaşlanmanın anlamına ilişkin daha eleştirel bir anlayışa sahiptir (Boyle vd., 2015; Cutchin, 2001). Bu anlayış, dezavantajlı veya zor yerlerde yaşamanın sonuçlarını anlama ihtiyacını da içermektedir (Scharf vd., 2005; Smith vd., 2004). Genel olarak, bu eleştirel coğrafi yaklaşımlar, yaşlılık, yaşlanma ve yaşlanan bedenlerin damgalanmasına ve tektipleştirilmesine itiraz etmektedir (Grenier, 2005; Wiles, 2011). Bu karşı çıkış, hem genel olarak toplumu hem de yaşlıları pasif ve bağımlı ve zayıf olarak gösteren, yaşl1larla ilgili olduğu halde onlara söz hakkı tanımayan ya da yaşl1lı̆̆ tedavi edilmesi gereken tıbbi bir sorun olarak gören araştırmalaradır. Eleştirel coğrafi yaklaşımlar, yaşlılık döneminin tek düze/tek tip olmadığını kabul etmektedir. Bunun yanında bu yaklaşımlar, yaşlanan bedenlere ve onların geniş bir yelpazeye yayılan mekânları (ev, mahalle, topluluk, bahçeler, boş zaman, iş ve eğitim alanları veya politik mekânlar gibi) ve sosyal bağlamları nasıl şekillendirdiğine ve onlarla nasıl ilişkili olduğuna daha fazla dikkat etmektedir. Bu çalışmalardan bazıları, bakım ve desteğin tek yönlü olmadığını, daha ziyade iki yönlü bir değiş-tokuş olduğunu ve yaşlı insanların hem ailelerine hem de yaşadıkları yerlere önemli katkılarda bulunduğunu göstermektedir (Milligan ve Wiles, 2010; Stephens vd., 2015; Wiles ve Jayasinha, 2013).

Yaşl1ların sağl1k coğrafyası alt alanında, özellikle yaşlı nüfusun ölümlülüğünün (mortality) ve hastalıklılığının (morbidity) mekânsal analizi ile ilgilenen sağlık coğrafyacılarının, demografların ve epidemiyologların makro ölçekli nicel çalışmalarına da rastlanmaktadır. Bu çalışmalar, küresel ve uluslararası sağlık, yaşam beklentisi eşitsizliklerine, ölüm nedenlerine ve yaşlılığa özgü hastalıklar ve bunama gibi rahatsızlıklara odaklanmaktadır. Küresel ölçekteki çalışmalarda yaşam tablolarının yardımıyla yaşlıların sağlık paternleri ortaya çıkarılmış (WHO, 2002a), yaşlı nüfusların küresel ve bölgesel ölümlülük ve hastalıklılık paternlerinin dökümü yapılmıştır (Ineichen, 1998; Russ vd., 2012; Suh \& Shah, 2001; Wimo vd., 2003; WHO, 2008). Birleşmiş Milletler'in ve Dünya Sağlık Örgütü’nün son zamanlarda yürüttüğü bazı küresel çalışmalar da bu bağlamda katkı sunmaktadır (örn. WHO, 2018). 
Ulusal ve karşılaştırmalı çalışmalarda, ileri yaşa özel ölümlülük eğilimlerine (Warnes, 1999), daha uzun yaşamanın, daha iyi veya daha kötü sağlıkla ya da yaşamın son aşamalarındaki, Fries'in (1980) hastalıklılık baskısı (compression of morbidity) dediği şeyle ilişkisine (McCracken \& Phillips, 2005), farklı ülkelerdeki yaşlıların sağlığı konusunda sosyo-ekonomik eşitsizliklere (bkz. Janssen, vd., 2006), ölümlülük ile sosyo-ekonomik paternler arasındaki ilişkiye, yaşlı ölümlerindeki cinsiyet farklılıklarına ve eğilimlere odaklanılmıştır (Gjonça vd., 2005). Yaşlı sağlı̆̆ının coğrafi boyutları üzerine yapılan çalışmaların çoğu ise, ulus-altı düzeyde gerçekleştirilmiştir (örn. Draper vd., 2004; Fukuda vd., 2005; Langford ve Bentham, 1996; Reid ve Harding, 2000).

Gelişmiş ülkelerde sağlık, hastalık, ölümlülük, yaşlı nüfus ve yaşlanma konularında atlas oluşturma eğiliminden de söz edilebilir. Amerika Birleşik Devletleri Ölümlülük Atlası (Atlas of United States Mortality) bunların en kapsamlılarından biridir (Pickle vd., 1996). Avrupa Sağlık Atlası (Atlas of Health in Europe), Avustralya Sosyal Sağlık Atlası (Social Health Atlas of Australia) (Glover vd.,1999; Glover vd., 2006), Kanada Yaşlanma Atlası (Atlas of the Aging Population of Canada) (Geographies of Aging Projects Lab, 2018) diğer örnekleri oluşturmaktadır.

Sağlık araştırmalarının bazılarında çok-katmanlı modelleme teknikleri, sağlık çıktıları üzerinde yerin bireysel ve bağlamsal etkilerini ortaya çıkarmak için kullanılmaktadır. Ciddi kronik bozuklukların çoğu, genellikle ilgili nüfusun tüm ömrü boyunca biriken deneyimlerin sonucu olarak görüldüğünden yer ve sağlık konusundaki araştırmalarda, yaşam gidişi yaklaşımının kullanım düzeyi de artmıştır.

\subsection{Sağlık ve Sosyal Bakım Hizmetleri}

Coğrafi gerontoloji, yaşlılar ile bulundukları mekânların/yerlerin birbiriyle güçlü biçimde bağlantılı olduğu ilkesini benimsemektedir. İnsan-yer bağı, sayısız yaşam olayının içinde üretilmekte ve güçlendirilmektedir. Ancak, gündelik sosyal mekânlarda bakım ve destek ağlarının birbiriyle iç içe geçmesi, özellikle önemlidir. İnsanlar genellikle yaşlandıkça daha fazla sağlık hizmetine ve sosyal desteğe ihtiyaç duymaktadır. Yaş spektrumunun her iki ucu (çocuklar ve yaşlılar) da sağlık hizmeti alma konusunda öne çıssa da grup olarak yaşlılar sağlık hizmetlerinin sık ve yoğun kullanıcıları durumundadır (World Health Organization-WHO, 2002b). Örneğin Kanada'da, 65 yaş ve üstü nüfus için kişi başına düşen kamusal sağlık hizmeti harcamasının 20 ila 64 yaşlar arasındaki nüfusun 4,5 katı olduğu ve sağlık hizmeti harcamalarının, yaş ilerledikçe yoğunlaştığı belirlenmiştir (Canadian Institute for Health Information, 2011).

Öte yandan sağlık hizmeti ve sosyal destek beklentisi, zamanla insanların ev, mahalle, topluluk, bölge ve aslında daha geniş topluluk ve insanlık kavramlarıyla olan ilişkileri hakkında düşündükçe ve davranış sergiledikçe daha fazla ağılık kazanmaktadır (Hanlon, 2018). Çeşitli sağlık hizmetlerine ve sosyal desteğe erişimi mümkün kılan bir yerde yaşamak, özellikle yaşamın ileri aşamalarındaki kişilerin güvenlik ve aidiyet duygusu için çok önemlidir (WHO, 2007). Sağllk hizmetlerine erişilebilirliğin (yere) yerleştirilmesi (emplacement), birinin kişilerarası ilişkilerinin kalitesi, sosyal olarak bağlantılı olma derecesi, refah, özsaygı ve kimlik duyguları da dâhil olmak üzere, şimdiki ve gelecekteki yaşam güzergâhları için dikkate değer etkilere sahiptir. Bu nedenle, sağlık hizmetlerine erişilebilirliğin farklı yönleri (örneğin, bulunabilirlik, güvenilirlik, uygunluk) coğrafi gerontolojinin belirgin ilgi alanları arasindadir (Hanlon, 2018). 
Yaşlı insanlara yönelik kamu, özel ve toplum temelli kaynakların mekânsal tahsisi ve kullanımı, planlanması ve düzenlenmesi konularına da yerleşik bir ilgi vardır. Bu araştırma alanı, mekânsal ölçekleri dikkate alan coğrafyacıların yakından ilgilendiği bir konudur. Sağlık coğrafyacıları ve sosyal coğrafyacılar ile sosyal gerontologlar tarafindan yapılan nicel çalışmalar, yaşlı insanların ihtiyaçlarının karşılanmasıyla ilgili olarak sağlı sistemlerinin mekânsal tasarımına ve etkilerine önem vermektedir. Coğrafya içerisinde bağımsız olarak geliştirilen bu çalışma alanının odak noktası, ulusal ve alt ulusal ölçeklerde yaşlılara yönelik hizmetlerin dağıtımı ve planlamasından, sağlık politikası reformlarının etkilerine ve yaşlı hizmetlerinin erişilebilirliği ve kullanımına ilişkin ekonomik yeniden yapılanma konularaına kadar değişmektedir (Andrews vd., 2007). Bazı çalışmalar, sağlı ve sosyal bakım hizmetlerinin sürekliliğine odaklanmakta; sağlık ve sosyal bakımın politik ekonomileri içinde gönüllülüğün desteklenmesi, yanı sıra piyasa düzenlemeleri yönündeki geniş çaplı değişiklikler açısından etkileri kavramsallaştırılmaktadır (Skinner ve Rosenberg, 2005).

Hizmetlerin verildiği politik ve kurumsal yapıların, özellikle formel ve enformel bakım (Milligan, 2006; Wiles, 2003a ve 2003b) ve hizmet planlama ve düzenlemedeki değişikliklerin kırsal etkilerini anlamaya yönelik incelemelere dikkat verilmektedir. (Skinner, 2008; Skinner ve Joseph, 2007; Skinner vd., 2008). Sosyal gerontologların sağlık hizmetleri, planlama ve düzenleme araştırmalarına yaptıkları katkılar, çok fazla olsa da (örn. Bane ve Bull, 2001; Heenan, 2006; Wolf ve Ballal, 2006), buradaki ana gelişme, nüfus yaşlanmasının kamu politikası bakımından sonuçları üzerinedir. Bu alanda coğrafi gerontolojinin büyük bir potansiyele sahip olduğu görülmektedir (Andrews vd., 2007).

\subsection{Sağlıklı Yaşlanmanın İnşası ve Temsilleri}

Son yıllarda, özellikle sosyal ve kültürel coğrafya içinde, yaşlanmaya ilişkin coğrafi ilginin kapsamı genişlemiş ve derinleşmiş, zengin kuramsal ve metodolojik çoğulculuk ve belirgin bir yaklaşım çeşitliliği ortaya çıkmıştır (Andrews vd., 2007; 2009). Aynı zamanda vücut bulmuş/somutlaşan (embodied) ve duygusal (emotional) coğrafyalar şemsiyesi altında, yaşlıların gündelik gerçekliklerine, gösterilen ilgi artmıştır (Anderson ve Smith, 2001; Hopkins ve Pain, 2007). Böylece, sosyal coğrafyacılar, sosyal gerontologlar ve sosyologlar, yaşlıların karmaşık yer bağlılığını ve kimliğini, bu yerleri nasıl paylaştığını değerlendirmek üzere bu alan altında bir araya gelmiştir. Yaşlanmanın, vücut bulmanın/somutlaşmanın (embodiment) ve yaşlı kimliklerinin nasıl temsil edildiğiyle ilgili çeşitli çalışmalar yapılmaktadır.

$\mathrm{Bu}$ konudaki çalışmalardan bazıları, yaşlı insanların sağlık, esenlik ve yaşlanma algılarını keşfetmeye gayret etmektedir. Araştırmalarda yaşlı insanlar için standart hale getirilmiş hastalık, maluliyet ya da sakatlık kavramlarının nasıl ve hangi bağlamda inşa edildiği de incelenmektedir (Andrews vd. 2007). Bazı çalışmalar, yaşı insanların, aktif olarak boş zaman aktivitelerine katılımı ile yaşlanma, bağımlılık, hareketsizlik ve sakatlık gibi yaşlanma yapılarına karşı mücadele arasındaki bağlantıyı ortaya çıkarmaktadır (Mansvelt, 1997). Yaşlanma ve yaşlanma yerlerinin temsilinin, yaşlanmayla ilgili toplumsal tutum ve değerleri nasıl ortaya çıkardığı da anlaşılmaya çalışılmaktadır. Yaş ayrımcılığı (ageism) bağlamında, yaşlıların özel yerlere (emekli köyleri, özel evler, bakım evleri ve diğer kurumsal ortamlara) yerleştirilmesi ile onların kamusal alandaki görünmezliği arasındaki ilişki de araştırma konusu olmaktadır. 


\section{Sonuç Yerine}

Yaşlı bir toplum olmaya artan hazırlanma ihtiyacı, coğrafi araştırmaların ufkunu genişletmesi için hem firsatlar hem de zorluklar getirmektedir (Macey vd., 2003). Bu yazı, yeni bir çalışma alanı olarak coğrafi gerontolojinin, yani yaşlanmanın coğrafyalarının toplumsal bağlam ve özellikle coğrafya ve gerontoloji disiplinleri açısından önemini ve canlandırılma gerekliliğini vurgulayan bir çağrı niteliği taşımaktadır. Coğrafi gerontoloji alanı, gerçekten de yaşlı insanların yaşamlarının ve deneyimlerinin hem şekillendiği hem de şekillendirildiği çok katmanlı, dinamik, tarihsel ve mekânsal olarak kavramsallaştırılmış bir süreç olarak yerin(place) rolüne ilişkin anlayışa katkıda bulunmak için araştırmacılara önemli bir potansiyel sunmaktadır.

Çağdaş bir dizi felsefi ve metodolojik çerçeve yardımıyla yaş, mekân ve yer arasındaki ilişkinin araştırılmasından sonra, yaşlanmanın, vücut bulmuş(embodied), bir yere yerleştirilmiş(emplaced) ve ilişkisel olarak tanımlanmış olması ve bunun Batılı araştırmacılar arasında artık sıra dışı bir durum olarak görülmemesi (Milligan ve Tarrant, 2018), bize burada yaşlanmanın coğrafyaları için ilişkisel (relational) ve duygusal (emotional) coğrafya yaklaşımlarına odaklanmanın yararlı olabileceğinin altını çizme cesareti vermektedir.

İlişkisel düşünme, mekânların ve yerlerin ancak diğer mekânlarla ve yerlerle olan bağlantılarıyla birlikte ortaya çıktığını kabul etmektedir (Skinner vd., 2015). Bu, belirli mekânlarda ve yerlerde bulunan ya da bunlarla ilişkili olan her şeyin (insanlar, nesneler, fikirler, politikalar, vb.), çoğu zaman farklı ölçeklerde, başka mekânlarda ve yerlerde bulunan şeylere de bağlanması gerektiğine işaret etmektedir. Duygusal coğrafya ise, duygular ile yer veya mekân arasındaki dinamik, tekrarlanan ilişkileri incelemektedir. Bu nedenle duygusal coğrafya, yaşanan yerin coğrafyalarının oluşturduğu duyguların, farklı ilişkilerin bir parçası haline gelmesiyle, farklı devinimlerin belirli sosyo-mekânsal düzenlerden ve etkileşimlerden nasıl ortaya çıktığını ve yeniden üretildiğini anlatmaktadır (Anderson, 2009). İlişkisel ve duygusal yaklaşımlar yardımıyla, her bir yaşlı kişinin çeşitli yönlerinin sosyal olarak inşa edilmiş, dinamik yerlerde gömülü veya oralarda yerleşik olarak anlaşılması; başka bir deyişle, yaşlıların sosyal ve kültürel coğrafyalarının belirli yerlere ayrılmaz biçimde gömülü olduğuna dikkat edilmesi önemlidir (Wiles, 2018).

Yaş1 ilişkisel olarak düşünürken; nesillerarasılık, kesişimsellik ve yaşam gidişi gibi teorik çerçevelerden ve temsili olmayan teorilerden de yararlanılabilir. Çağdaş beşeri coğrafyacılar, evden ve bahçeden, topluluğa, çeşitli kırsal ve kentsel formlara kadar çeşitli ölçeklerin ve çevrelerin yaşlanma ve yaşl1lık dönemi için önemine işaret etmektedir. $\mathrm{Bu}$ tür çalışmalar, sadece pozitif yaşlanmayı desteklemek için belirli çevrelerin önemini değil, fakat aynı zamanda yaşlı insanların bu çevrelerle olan ilişkilerindeki değişikliğin onların yer duygusunu ve aidiyetini etkileyebileceğini de dile getirmektedir. Yaşanılan ev, topluluk, mahalle, kırsal veya kentsel yaşam çevreleri, insanların başarılı şekilde, yerinde yaşlanması için önemli roller üstlenmektedir. Bu nedenle bu tür çevreler de yaşlanma araştırmalarında özel bir ilgiyi hak etmektedir. 


\section{Notlar}

1.Sosyal tıp, toplumun sağlığını ve sağlık sistemini daha geniş bir sosyal bağlamda inceleyen tıp alanının bilimsel, disiplinler arası bir dalıdır. Bu dal, sağlığın belirleyicilerinin anlaşılmasına ve bu bilginin nüfusun sağlığını iyileştirmek için en iyi şekilde nasıl uygulanacağına katkıda bulunmaktadır (Kostičová, 2015: 10).

2.Türkiye'de yayınlanan bazı çalışmalarda (Esendemir, 2015, 2016), coğrafi gerontoloji yerine mekân gerontolojisi isminin kullanıldığı gözlenmektedir (2016 tarihli çalışmanın İngilizce özetinde, geographical gerontology şeklinde kullanıldığı halde). Oysa coğrafi sıfatı, mekânı, yeri, lokasyonu, bölgeyi, alanı ve benzerlerini kapsayacak genişlikte bir nitelemedir ve mekân gerontolojisi, coğrafi gerontolojinin anlamını ve kapsamını kucaklamamaktadır.

3. Embodied sözcügü, bir fikir, nitelik ya da duyguya somut ya da görünür bir form verme ya da onların bir ifadeye sahip olması veya fiziksel bir form ile bir maneviyat sağlama anlamına gelmektedir.

4. Congregate housing sözcüğü, her bireyin ya da ailenin özel bir yatak odası ya da yaşam alanına sahip olduğu, ancak diğer sakinlerle ortak bir yemek odası, dinlenme odası ya da diğer tesisleri paylaştığı bir konut türünü tanımlamaktadır.

\section{Bilgilendirme}

Bu makale, 3-6 Ekim 2018 tarihleri arasında Ankara Üniversitesi Türkiye Coğrafyası Araştırma ve Uygulama Merkezi'nin düzenlediği “International Geography Symposium on the 30th Anniversary of TUCAUM" başlıklı bilimsel etkinlikte sunulmuş bir bildirinin genişletilmiş ve geliştirilmiş halidir. 
To cite: Özgür, E. M. (2019). The Geographies of Ageing: Process, Debates and Research Agenda in Geographical Gerontology, Coğrafi Bilimler Dergisi/ Turkish Journal of Geographical Sciences, 17(1), 78-109, doi: 10.33688/ aucbd.512325

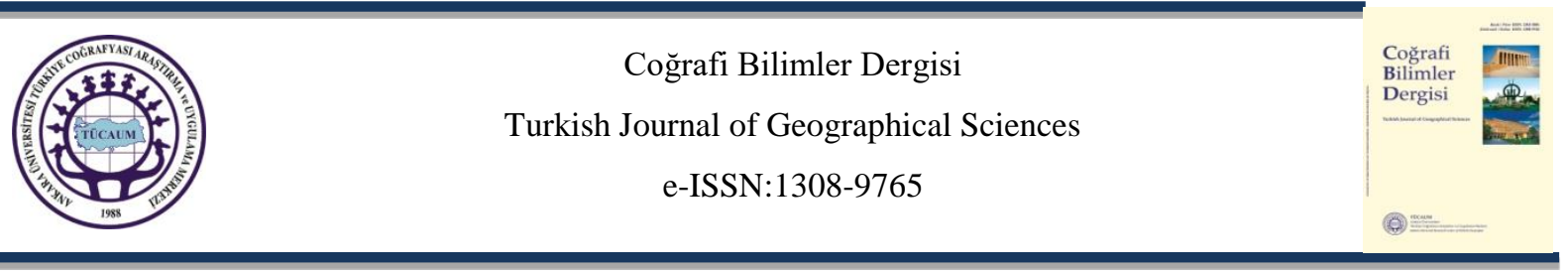

\section{The Geographies of Ageing: Progress, Debates and Research Agenda in Geographical Gerontology}

Ertuğrul Murat Özgür*a

Accepted: 26.03.2019

\section{EXTENDED ABSTRACT}

\section{Introduction}

Population ageing -closely linked to a decrease in fertility and an increase in life expectancy- is a global phenomenon changing the demographic structure of the world (Kinsella and Velkoff, 2001; Lutz et al., 2008a, 2008b; McCracken and Phillips, 2005; United Nations-UN, 2007a, 2007b). In recent years, Turkey's population has also displayed a tendency towards ageing, and serious shifts have occured in the national age structure (Behar, 2006; Eryurt, 2014; Türkiye İstatistik Kurumu-TÜİK, 2015). The Turkish public is now considered to be an elderly society, and Turkey's ageing process is expected to be completed in 15-20 years (Arun, 2013).

Around the world, individuals, families, communities, organizations, companies, industries, governments and the civil society face the opportunities and challenges of an unprecedented number of elderly people (Skinner et al., 2018). Population ageing is expected to influence economic (growth, savings, investments, consumption, workforce market, retirement funds, taxation and intergenerational transfers, etc.) as well as the social (family composition and life arrangements, housing demands, migration tendencies, epidemiology and health care needs, etc.) and political (election patterns and political representation, etc.) areas (Harford, 2009; Lutz et al., 2008a; UN, 2007a). Population ageing and issues relating to an elderly population, particularly those concerning their integration into society, and the increase of functionality and life quality, will likely become a significant socio-demographic concept in the 21st century on a global and national scale (Devlet Planlama Teşkilat1-DPT, 2007).

Geography is one of the many active disciplines in ageing studies conducted in developed countries of the world. The role of geographical research among ageing studies was acknowledged following the studies of the early 1970s, which revealed that the environment influenced the ageing process (Sylvestre, 1999). A new discipline positioned at the intersection of geography and gerontology, and is known as geographical gerontology, has been developing structurally in institutions and intellectually in academic debates in the disciplines as well as in noteworthy empirical studies. This contemporary field of research has created a common interest area under the name geographies of

\footnotetext{
*Corresponding Author: ozgur@ankara.edu.tr.

aAnkara University, Faculty of Language, History and Geography, Department of Geography, Ankara, Turkey, https://orcid.org/0000-0002-2146-7721
} 
ageing with the influence of a long-term tradition in human geography and more recently with that of a spatial turn observed in social gerontology (Skinner et al., 2018).

Members of many disciplines in Turkey have an increasing interest in the topic of ageing. Although scholars from many different disciplines have shown an increasing interest in the topic of ageing, there has only been a limited number of studies. According to Arun, ageing has not adequately penetrated the socio-political and academic agenda or formed its own, and for this reason, the risks and opportunities of ageing needs to be discussed (Arun, 2018: 42-43). This article aims to attract the interest of human geographers and members of other disciplines to geographical gerontology and the recent efforts of Turkey's ageing population to find their place in the social, political and academic agenda of the country by summarizing the developments in the academic studies focusing on the geographies of ageing, and to stress contemporary discussions and research agenda in the relevant field.

\section{Progress in Geographical Gerontology and the Geographies of Ageing}

With regard to research, an intersection has existed between human geography and social gerontology since the 1970s (Andrews et al., 2009). This intersection stems from classical studies by social psychologists (Lawton and Simon, 1968) on the environmental pressure elements on the elderly and research by geographers concerning where the elderly live and their daily spatial lives (Golant, 1972; Rowles, 1978). Following 40 years of continued research and progress in developed countries, the intersection has now become rather comprehensive under the heading 'geographical gerontology' and has come to include ethnographic micro-sociology, environmental psychology, demography, migration studies, urban planning and architecture (Cutchin 2009; Rudzitis 1984; Wahl and Wiesman, 2003). Geographical gerontology is proposed as a comfortable place to co-develop theories, concepts and empirical knowledge on the relationships between space, place and ageing (Andrews et al. 2007).

As a result, it has now turned into a growing interdisciplinary academic field which enables the application of geographical perspectives, concepts and approaches in ageing, old age, and elderly population studies conducted by allied geographers, gerontologists, health and social scientists (Skinner et al., 2018). Geographical gerontology is supported by the two main disciplines in the geographies of ageing: human geography and social gerontology. The subfields of human geography which contribute significantly to geographical gerontology include health geography, population geography, social geography, critical geography, cultural geography and urban geography, while those in the social gerontology include critical gerontology, cultural gerontology and environmental gerontology, health and social services, social theories of ageing and life course studies. At the focus of geographical gerontology research lie many diverse topics ranging from the spatial patterns of demographic ageing to health care services and infrastructure; life arrangements and the environment of the older people to the place-embedded experiences of ageing, health, care, and well-being and more recently to the embodiment and representation of experiences in the field.

\section{Current Debates and Research Agenda in Geographical Gerontology}

In recent years, North American and European human geographers from both the positivist and critical tradition have been contributing more to the debate surrounding geographies of ageing (Hardill, 2009). Certain geographical studies attempt to understand the spatial patterns of ageing and service provision with an empirical positivist approach, and migration from the perspective of life course. Some 
others are fed by feminist, post-structuralist and post-modernist approaches when conceptualizing ageing and space. In relation to these, particularly in social and cultural geography, the scope of the interest in ageing expands and deepens, and a rich theoretical and methodological pluralism and a distinct diversity of approach emerges (Skinner et al., 2015). At the same time, the interest in the elderly increases under the umbrella of embodied and emotional geographies and with regard to their daily realities (Anderson and Smith, 2001; Hopkins and Pain, 2007).

Some studies in the discipline of geographical gerontology reveal trends in demographic ageing, the distribution of the elderly population in various geographical scales (global, international, national and subnational) and the changes in these, as well as migration/mobility patterns. Findings from these studies are associated with various economic, environmental, financial, social and health-related problems and relevant policies. Some studies focus on elderly migration, mobility and their geographical proximity to their relatives. Such studies attempt to explain the nature, effects and results of elderly geographical mobility; and define the relationship between their geographical proximity to their relatives and the quality of their interaction (e.g. Glaser and Tomassini, 2000; Glaser et al., 2004; Hank, 2007; Lin and Rogerson, 1995; Michielin and Mulder, 2007; Shelton and Grundy, 2000; van der Pers et al., 2015).

The life environments of older adults are also on the research agenda of geographical gerontology. Research into this topic increasingly include qualitative studies by health geographers, environmental psychologists and sociologists. These studies particularly examine the non-medical aspects of elderly health, and the effects of place and the environment on health (Andrews et al., 2007). Research also concerns itself with various issues ranging from the special life environments needed by the elderly (homes and residential areas) and the interactions within these environments, to the contextual aspects of the environments, places and communities in which the elderly live, work, spend their time and receive care (Andrews vd., 2009). These studies also focus on how a home, neighborhood, city center or rural settlement may be transformed into appropriate and healthy environments for the elderly (e.g.. Michael et al., 2006; Phillips et al., 2005; Walter-Ginzburg et al., 2004). The Age-friendly Environments approach, initiated by the World Health Organization (WHO) in 2005 and describing an environment conducive to active ageing, is also becoming increasingly popular in studies (WHO, 2017).

Considering the spatial contexts where ageing takes place, the geographies of ageing accept that older adults prefer to stay in their own homes and to age in one place as much as possible (Skinner et al., 2015). Similarly, geographies of care evaluate the spatial context of difficulties of caring for the weak and vulnerable elderly, including experiences of giving and receiving. According to this, the home seems to be a particularly important location for providing? and receiving care services. The daily living spaces of the elderly are assumed to shrink step by step until they turn into prisoners of space. The increased interest of both geographers and gerontologists in this topic may be attributed to its relationship with the concept of place in the daily experiences of the elderly and care services (Milligan, 2000; Peace et al., 2006; Wiles, 2005). Such studies not only reveal the changing nature and experience of home and society with increased age and vulnerability, but also emphasize the importance of context and place attachment in supporting and maintaining elderly autonomy and sense of identity. At this point, two closely related, even overlapping, concepts emerge in the political arena and the literature: ageing in place and place attachment. 
The health geographies of ageing is a main sub-theme of geographies of ageing. Geography is an important element of the ageing process. While ageing shapes health geographies on one hand, health geographies keep shaping ageing on the other. The health geographies of ageing have moved away from the previous tendency of considering health in a biomedical context, to adopting more holistic socioecological approaches towards ageing and health in social, physical and symbolic contexts. By examining the relationship between people and their physical, social and symbolic environments, health geographers focus on the distribution of and engagement with health, illness and a wide variety of resources for health, ranging from the human body to regional and global scales (Wiles, 2018). The subfield of the health geographies of ageing includes macro-scale quantitative studies by health geographers, demographers and epidemiologists who are particularly interested in the spatial analysis of elderly mortality and morbidity. These studies focus on global and international health, life expectancy inequalities, mortality reasons, age-related diseases and illnesses such as dementia.

One of the main principles of geographical gerontology is that there is a deep and mutual link between elderly individuals and space and place. The human-place bond is produced and strengthened within innumerable life events; however, it is particularly important that care and support networks are intertwined in daily social spaces. As people age, they generally need more health care and social support. There is a settled interest in the spatial allocation of public, private and society-based resources for the elderly, and their use, planning and arrangement. This is a specially attractive field of research for geographers who consider spatial scales. The focal point of this field ranges from the distribution and planning of services for the elderly at a national and subnational level, to the effects of health policy reforms and economic restructuring for the accessibility and use of services by the elderly (Andrews vd., 2007).

Within the scope of embodied and emotional geographies, social geographers, social gerontologists and sociologists evaluate the complex place attachment and identities of the elderly, and how they share these places. Various studies are being conducted into ageing, embodiment and how elderly identities are represented. Some such studies try to discover elderly people's health, well-being and ageing perceptions. The studies also examine how, and in what context, the concepts made standard for the elderly such as illness, incapacity or disability are constructed (Andrews vd. 2007). Several studies have revealed the ties between the active participation of the elderly in spare time activities and the fight against ageing, dependence, immobility and disability (Mansvelt, 1997). There are also attempts 1 to understand how the representation of ageing and places of ageing shed light on age-related social attitudes and values. As regards ageism, the connections between settling the elderly in special places (retirement villages, nursing homes or other institutions) and their invisibility in the public area are also being studied.

\section{Concluding Remarks}

The increased need to prepare for an ageing society presents both an opportunity and a challenge for an expansion in geographical research (Macey vd., 2003). This paper is a call to emphasize the importance of and initiate geographical gerontology, or the geographies of ageing, as a new study area in relation to social context and particularly the disciplines of geography and gerontology. Indeed, geographical gerontology presents geographers with a potential to contribute to the understanding of the 
role of place as a multilayered, dynamic, historically and spatially conceptualized process, in which the lives and experiences of the elderly both take shape and are shaped.

The fact that ageing has been defined as embodied, emplaced and relational after studying the relationship between age, space and place through a modern set of philosophical and methodological frameworks gives us the courage to claim here that focusing on relational and emotional geography approaches may be useful for the geographies of ageing. It is important to perceive each elderly individual's various aspects as socially constructed, and embedded or settled in dynamic places with the help of relational and emotional approaches; in other words, to note that the social and cultural geographies of the elderly are inseparably embedded in certain places (Wiles, 2018).

When age is considered relationally, theoretical frameworks such as intergenerationality, intersectionality or life course and non-representational theories may also be used. Contemporary human geographers point out the importance of various scales and environments from the home and garden to community, and other rural and urban forms in ageing. Such studies reveal not only the importance of certain environments in supporting positive ageing, but also that changes in the relations of the elderly with these environments may also affect their sense of place and belonging. The home, community, neighborhood, rural or urban life environments that people live in play important roles in successful ageing in place. Therefore, such environments deserve special mention in ageing research.

\section{Referanslar/References}

Akgül, H. (2018). Aksu İlçesinde(Isparta) Kırsal Nüfusun Yaşlanması ve Yaşlı Nüfusun Sorunları. Isparta: Süleyman Demirel

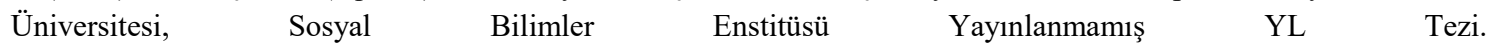
https://tez.yok.gov.tr/UlusalTezMerkezi/tezSorguSonucYeni.jsp adresinden edinilmiştir.

Anderson, B. (2009). Emotional Geography. Derek Gregory, Ron Johnston, Geraldine Pratt, Michael J. Watts ve Sarah Whatmore (Eds.), The Dictionary of Human Geography içinde (5. Bask1), (188-189). Wiley-Blackwell.

Anderson, K., Smith, S.J. (2001). Emotional Geographies. Transactions of the Institute of British Geographers 26 (1), 7-10. doi:10.1111/1475-5661.00002

Andrews, G.J., Phillips, D.R. (2005). Geographical Studies in Ageing: Progress and Connections to Social Gerontology. Gavin J. Andrews ve David R. Phillips (Eds.), Ageing and Place: Perspectives, Policy, Practice içinde (7-12). Londra: Routledge.

Andrews, G.J., Cutchin, M., McCracken, K., Phillips, D.R., Wiles, J. (2007). Geographical Gerontology: The Constitution of a Discipline. Social Science \& Medicine, 65, 151-168. doi: 10.1016/j.socscimed.2007.02.047

Andrews, G.J., Milligan, C., Phillips, D.R., Skinner, M.W. (2009). Geographical Gerontology: Mapping a Disciplinary Intersection. Geography Compass, 3(5), 1641-1659. doi:10.1111/j.1749-8198.2009.00270.x

Andrews, G.J., Evans, J., Wiles, J.L. (2013). Re-spacing and Re-placing Gerontology: Relationality and Affect. Ageing \& Society, 33, 1339-1373. doi:10.1017/S0144686X12000621

Andrews, G.J., Skinner, M.W., Cutchin, M.P. (2018). Space and Place in Geographical Gerontology: Theoretical Traditions, Formations of Hope. Mark W. Skinner, Gavin J. Andrews, Malcolm P. Cutchin (Eds.), Geographical Gerontology: Perspectives, Concepts, Approaches içinde (11-28). New York: Routledge.

Arun Ö. (2013). Ageing in Turkey: “The Peter Pan Syndrome?”. Joseph Troisi, Hans-Joachim von Kondratowitz (Eds.), Ageing in the Mediterranean içinde (297-323). London: Policy Press.

Arun, Ö. (2018a). Türkiye'de Yaşlanmak: Bir Armağan ya da Lanet?. Özgür Arun (Ed.), Yaşlanmayı Aşmak içinde (23-52). Ankara: Phoenix.

Arun, Ö. (2018b). Türkiye'de Yaşlanma Çalışmaları: Dün, Bugün, Yarın. Mediterranean Journal of Humanities, 8(2), 41-61. doi:10.13114/MJH.2018.409 
Aslan, D. (2015). Yaşlı dostu kentler. Yaşlı Dostu Kentler Sempozyumu Bildiri Kitabı içinde (25-29). Ankara: Aile ve Sosyal Politikalar Bakanlığı, Engelli ve Yaşlı Hizmetleri Genel Müdürlüğü.

Avc1, S. (2014). Türkiye'de 65 ve Üzeri Yaştaki Nüfusun Gelişimi ile Mekânsal Dağıllışı. TÜCAUM VIII. Coğrafya Sempozyuтu (23-24 Ekim 2014) Bildiriler Kitabı içinde, (299-308). Ankara.

Avcı, S. (2016). Türkiye'de Yaşlı Nüfusun Artışının Neden Olduğu Sorunlar. TÜCAUM Uluslararası Coğrafya Sempozyumu 13-14 Ekim 2016 Bildiriler Kitabı içinde (597-598). Ankara.

Bane, S.D., Bull, C.N. (2001). Innovative Rural Mental Health Service Delivery for Rural Elders. Journal of Applied Gerontology 20, 230-240.

Behar, C. (2006). Demographic Developments and "Complementarities”: Ageing, Labor and Migration. Turkish Studies, 7(1), 17-31. doi:10.1080/14683840500520543

Boyle, A., Wiles, J.L., Kearns, R.A. (2015). Rethinking Ageing in Place: The 'People' and 'Place' Nexus. Progress in Geography (China), 34(12), 1495-1511. doi:10.18306/dlkxjz.2015.12.002

Bradley, D.E., Van Willigen, M. (2010). Migration and Psychological Well-Being among Older Adults: A Growth Curve Analysis Based on Panel Data from the Health and Retirement Study, 1996-2006. Journal of Aging and Health, 22(7), 882-913. doi:10.1177/0898264310368430

Buffel, T., Phillipson, C. (2018). Urban Ageing: New Agendas for Geographical Gerontology. Mark W. Skinner, Gavin J. Andrews, Malcolm P. Cutchin (Eds.), Geographical Gerontology: Perspectives, Concepts, Approaches içinde (123135). New York: Routledge.

Cagney, K.A., Browning, C.R., Wen, M. (2005). Racial disparities in self-rated health at older ages what difference does the neighbourhood make?. The Journals of Gerontology Series B: Psychological Sciences and Social Sciences, 60(4), 181190.

Canadian Institute for Health Information-CIHI (2011). Health Care in Canada, 2011: A Focus on Seniors and Aging. Ottawa: CIHI.

Casado-Diaz, M., Kaiser, C., Warnes, A. M. (2004). Northern European Retired Residents in Nine Southern European Areas: Characteristics Motivations and Adjustment. Ageing and Society, 24 (3), 353-381. doi: 10.1017/S0144686X04001898

Choi, S.J. (2009). Ageing Society Issues in Korea. Asian Social Work and Policy Review, 3(1), 63-83. doi:10.1111/j.17531411.2008.00025.x

Cook, I.G., Halsall, J. (2011). Aging in Comparative Perspective: Processes and Policies. New York: Springer.

Cutchin, M. (2001). Deweyan Integration: Moving Beyond Place Attachment in Elderly Migration Theory. The International Journal of Aging and Human Development, 52(1), 29-44. doi:10.2190/AF2D-A0T4-Q14C-1RTW

Cutchin, M.P. (2009). Geographical Gerontology: New Contributions and Spaces for Development. The Gerontologist, 49(3), 440-444. doi: 10.1093/geront/gnp095

Dempsey, S., Devine, M.T., Gillespie, T., Lyons, S., Nolan, A. (2018). Coastal Blue Space and Depression in Older Adults. Health \& Place, 54, 110-117. doi:10.1016/j.healthplace.2018.09.002

Devlet Planlama Teşkilatı-DPT (2007). Türkiye’de Yaşlıların Durumu ve Yaşlanma Ulusal Eylem Planı. Ankara: DPT.

Diaz-Moore, K. (2018). Environment and Ageing. Mark W. Skinner, Gavin J. Andrews, Malcolm P. Cutchin (Eds.), Geographical Gerontology: Perspectives, Concepts, Approaches içinde (80-90). New York: Routledge.

Diez-Roux, A.V. (1998). Bringing Context Back into Epidemiology: Variables and Fallacies in Multilevel Analysis. American Journal of Public Health, 88(2), 216-222.

Diez-Roux, A.V. (2002). Invited Commentary: Places, People and Health. American Journal of Epidemiology, 155(6), 516519. doi:10.1093/aje/155.6.516

Draper, G., Turrell, G., Oldenburg, B. (2004). Health Inequalities in Australia: Mortality. Health Inequalities Monitoring Series No. 1. AIHW Cat. No. PHE 55. Canberra: Queensland University of Technology and the Australian Institute of Health and Welfare. 
Emiroğlu, M. (1988). Türkiye'de yaşlı nüfusun artışı ve coğrafi dağılım özellikleri. DTCF Coğrafya Araştırmaları Dergisi, 11, 25-49.

Eryurt, M.A. (2014). Türkiye'de Yaşlı Nüfus ve Yaşlılık Dönemiyle Ilgili Yaşam Tercihleri. Türkiye Aile Yapısı Araştırması: Tespitler, Öneriler içinde (88-109). İstanbul: TC Aile ve Sosyal Politikalar Bakanlığı.

Eschbach, K., Ostir, G.V., Patel, K.V., Markides, K.S., Goodwin, J.S. (2004). Neighbourhood Context and Mortality among Older Mexican Americans: Is There a Barrio Advantage. American Journal of Public Health, 94(10), 1807-1812. doi: 10.2105/AJPH.94.10.1807

Esendemir, Ş. (2015). Mekândan Doğru Yaşlılığı Okumak: Yeni Bir Mekân Gerontolojisine Doğru. Yaşlılık Atölyesi 20-21 Ekim 2015 / İstanbul, Bildiri Özetleri, (s.23).

Esendemir, Ş. (2016). Türkiye'de Yerinde Yaşlanma ve Mekân Gerontolojisinin Temel Parametreleri. [Aging in Place and the Basic Parameters of Geographical Gerontology in Turkey] Sosyoloji Dergisi, 36, 13-31. doi: 10.16917/iusosyoloji.284544

Fries, J.F. (1980). Aging, Natural Death, and the Compression of Morbidity. New England Journal of Medicine, 303(3), 130135.

Fukuda, Y., Nakamura, K., Tacano, T. (2005). Municipal Health Expectancy in Japan: Decreased Healthy Longevity of Older People in Socioeconomically Disadvantaged Areas. BMC Public Health, 5, 65. doi: 10.1186/1471-2458-5-65

Geographies of Aging Projects Lab (2018). Atlas of the Aging Population of Canada. http://gaplab.github.io/GAPLab/index.html

Gjonça, A., Tomassini, C., Toson, B., Smallwood, S. (2005). Sex Differences in Mortality, A Comparison of the United Kingdom and Other Developed Countries. Health Statistics Quarterly, 26(6), 6-16.

Glaser, K., Tomassini, C. (2000). Proximity of Older Women to Their Children: A Comparison of Britain and Italy. The Gerontologist, 40(6), 729-737.

Glaser, K., Tomassini, C., Grundy, E. (2004). Re-visiting Convergence and Divergence: Support for Older People in Europe. European Journal of Ageing, 1(1), 64-72. doi: 10.1007/s10433-004-0006-1

Glover, J. Harris, K., Tennant, S. (1999). A Social Health Atlas of Australia (2.bask1), Public Health Information Development Unit, Adelaide: University of Adelaide.

Glover, J., Hetzel, D., Glover, L., Tennant, S., Page A. (2006). A Social Health Atlas of South Australia. (3.bask1). Adelaide: The University of Adelaide.

Golant, S.M. (1972). The Residential Location and Spatial Behavior of the Elderly: A Canadian Example. University of Chicago Geography Research Papers.

Golant, S.M. (1984a). The Geographical Literature on Aging and Old Age: An Introduction. Urban Geography, 5(3), 262272.

Golant, S.M. (1984b). A Place to Grow: The Meaning of Environment in Old Age. New York: Columbia University Press.

Golant, S.M. (2015). Aging in the Right Place. Baltimore, MD: Health Professions Press.

Grenier, A. M. (2005). The Contextual and Social Locations of Older Women's Experiences of Disability and Decline. Journal of Aging Studies, 19(2), 131-146. doi:10.1016/j.jaging.2004.07.003

Gustafson, P. (2000). Tourism and Seasonal Retirement Migration. Annals of Tourism Research, 29(4), 899-918. doi: 10.1016/S0160-7383(01)00084-6

Gustafson, P. (2001). Retirement Migration and Transnational Lifestyles. Ageing \& Society, 21(4), 371-394. doi: https://doi.org/10.1017/S0144686X01008327

Gustafson, P. (2008). Transnationalism in Retirement Migration: the Case of North European Retirees in Spain. Ethnic and Racial Studies, 31(3), 451-475. doi:10.1080/01419870701492000

Hallman, B.C., Joseph, A. (1999). Getting There: Mapping the Gendered Geography of Caregiving to Elderly Relatives. Canadian Journal on Aging, 18(4), 397-414. doi:10.1017/S0714980800010011 
Hank, K. (2007). Proximity and Contacts between Older Parents and Their Children: A European Comparison. Journal of Marriage and Family, 69(1), 157-173. doi: 10.1111/j.1741-3737.2006.00351.x

Hanlon, N. (2018). Older Persons, Place and Health Care Accessibility. Mark W. Skinner, Gavin J. Andrews, Malcolm P. Cutchin (Eds.), Geographical Gerontology: Perspectives, Concepts, Approaches içinde (229-240). New York: Routledge.

Hardill, I. (2009). Introduction: Geographies of Aging. The Professional Geographer, 61(1), 1-3. doi: $10.1080 / 00330120802577509$

Harford, J. (2009). Population Ageing and Dental Care. Community Dentistry and Oral Epidemiology, 37(2), 97-103. doi: 10.1111/j.1600-0528.2008.00441.x.

Harper, S., Laws, G. (1995). Rethinking the Geography of Ageing. Progress in Human Geography, 19(2), 199-221. doi: $10.1177 / 030913259501900203$

Heenan, D. (2006). The Factors Influencing Access to Health and Social Care in the Farming Communities of County Down, Northern Ireland. Ageing and Society, 26(3), 373-391. doi: 10.1017/S0144686X06004697

Hopkins, P., Pain, R. (2007). Geographies of Age: Thinking Relationally. Area, 39(3), 287-294. doi: 10.1111/j.14754762.2007.00750.x

Ineichen, B. (1998). The Geography of Dementia: An Approach through Epidemiology. Health and Place, 4(4), 383-394.

Janssen, F., Kunst, A.E., Mackenbach, J.P. (2006). Association between Gross Domestic Product throughout the Life Course and Old-Age Morality across Birth Cohorts: Parallel Analyses of Seven European Countries, 1950-1999. Social Science \& Medicine, 63(1), 239-254. doi: 10.1016/j.socscimed.2005.11.040

Jones, M. (2009). Phase Space: Geography, Relational Thinking, and Beyond. Progress in Human Geography, 33(4), 487-506. doi: $10.1177 / 0309132508101599$

Joseph, A., Hallman, B.C. (1998). Over the Hill and Far Away: Distance as a Barrier to the Provision of Assistance to Elderly Relatives. Social Science \& Medicine, 46(6), 631-639. doi:10.1016/S0277-9536(97)00181-0

Kearns, R.A., Andrews, G.J. (2005). Placing Ageing: Positionings in The Study of Older People. In G.J. Andrews and D.R. Phillips (Eds.), Ageing and Place: Perspectives, Policy, Practice içinde (13-23). London: Routledge.

King, K., Newbold, B.K. (2009). Later-life Migration in Canada in 2001: A Multilevel Approach. Journal of Population Aging, 2(3-4), 161-181. doi: 10.1177/088541220201700103

King, R., Warnes, A.M., Williams, A.M. (1998). International Retirement Migration in Europe. International Journal of Population Geography, 4(2), 97-111. doi: 10.1002/(SICI)1099-1220(199806)4:2<91::AID-IJPG97>3.0.CO;2-S

Kinsella, K., Phillips, D.R. (2005). Global Aging: The Challenge of Success. Population Bulletin, 60(1), 1-40.

Kinsella, K., Velkoff, V.A. (2001). An Aging World: 2001. U.S. Census Bureau, Series P95/01-1, Washington DC: U.S. Government Printing Office.

Kobetz, E., Daniel, M., Earp, J.A. (2003). Neighbourhood Poverty and Self-Reported Health among Low-Income, Rural Women, 50 Years And Older. Health and Place, 9(3), 263-271. doi: 10.1016/S1353-8292(02)00058-8

Koç, İ. (2014). Türkiye'de Doğurganlık Seviyesi ve Örüntüsünün Değişimi: 1968-2011. Türkiye Aile Yapısı Araştırması: Tespitler, Öneriler içinde (170-195). İstanbul: TC Aile ve Sosyal Politikalar Bakanlığı.

Koç, İ. Eryurt, M.A. Adalı, T., Çağatay, P. (2010). Türkiye'nin Demografik Dönüşümü: Doğurganlık, Aile Planlaması, Anne Çocuk Sağllğı ve Beş Yaş Altı Ölümlerdeki Değişimler: 1968-2008. Ankara: HÜNEE.

Kostičová, M. (2015). Introduction to Social Medicine. Michaela Kostičová (Ed.), Social Medicine içinde (10-23). Comenius University in Bratislava.

Kontos, P.C. (1998) Resisting institutionalization: Constructing old age and negotiating home. Journal of Aging Studies, 12 , 167-184. doi: 10.1016/S0890-4065(98)90013-5

Kontos, P. (2005). Multi-disciplinary Configurations in Gerontology. Gavin J. Andrews, David R. Phillips (Eds.), Ageing and Place: Perspectives, Policy, Practice içinde (24-36). London: Routledge. 
Kurt, H. (2005). Avrupa Birliği Ülkelerinde Nüfusun Yaş Yapısı. S. Avcı ve H. Turoğlu (Eds.), Ulusal Coğrafya Kongresi, Prof. Dr. İsmail Yalçınlar Anısına (29-30 Eylül 2005) Bildiriler Kitabı içinde (277-287). İstanbul.

Lawton, M.P., Simon, B. (1968). The Ecology of Social Relationships in Housing for the Elderly. The Gerontologist, 8(2), $108-115$.

Langford, I. H., Bentham, G. (1996). Regional Variations in Mortality Rates in England and Wales: An Analysis Using Multilevel Modeling. Social Science \& Medicine, 42, 897-908.

Lewicka, M. (2008). Place Attachment, Place Identity, and Place Memory: Restoring the Forgotten City Past. Journal of Environmental Psychology, 28(3), 209-231.

Lin, G., Rogerson, P.A. (1995). Elderly Parents and the Geographic Availability of Their Adult Children. Research on Aging, $17,303-332$.

Low, S., Altman, I. (1992). Place Attachment: A Conteptual Inquiry. Irwin Altman, Setha M. Low (Eds.), Place Attachment (1-12). New York: Plenum Press.

Lutz, W., Sanderson, W.C., Scherbov, S. (2008a). Global and Regional Population Ageing: How Certain are We of Its Dimensions?. Population Ageing, 1, 75-97. doi: 10.1007/s12062-009-9005-5

Lutz, W., Sanderson, W., Scherbov, S. (2008b). The Coming Acceleration of Global Population Ageing. Nature, 451(7), 716719. doi:10.1038/nature06516

Macey, S.M., Smith, G.C., Watkins, J.F. (2003). Aging and the Aged. Gary L. Gaile, Cort J. Willmott (Eds.). Geography in America at the Dawn of the 21st Century içinde (514-523). Oxford: Oxford University Press.

Macintyre,S., Ellaway, E., Cummins, S. (2002). Place Effects on Health: How Can We Conceptualise, Operationalise and Measure Them? Social Science \& Medicine, 55(1), 125-139. doi: 10.1016/S0277-9536(01)00214-3

McCracken, K., Phillips, D.R. (2005). International Demographic Transitions. Gavin J. Andrews, David R. Phillips (Eds.), Ageing and Place: Perspectives, Policy, Practice içinde (36-60). New York: Routledge.

Mansvelt, J. (1997). Working at Leisure: Critical Geographies of Ageing. Area, 29(4), 289-298.

Martin-Matthews, A., Cloutier, D.S. (2018). Household Spaces of Ageing: When Care Comes Home. Mark W. Skinner, Gavin J. Andrews, Malcolm P. Cutchin (Eds.), Geographical Gerontology: Perspectives, Concepts, Approaches içinde(162173). New York: Routledge.

Michael, Y.L., Green, M.K., Farquhar, S.A. (2006). Neighborhood Design and Active Aging. Health \& Place, 12(4), 734-740. doi: $10.1016 /$ j.healthplace.2005.08.002

Michielin, F., Mulder, C.H. (2007). Geographical Distances between Adult Children and Their Parents in the Netherlands. Demographic Research, 17, 655-678. doi: 10.4054/DemRes.2007.17.22

Milligan, C. (2000). Bearing the Burden: Towards a Restructured Geography of Caring. Area, 32, 49-58. doi: 10.1111/j.14754762.2000.tb00114.x

Milligan, C. (2006). Caring for Older People in the 21st Century: Notes from a Small Island. Health \& Place, 12(3), $320-331$. doi: 10.1016/j.healthplace.2004.12.002

Milligan, C., Tarrant, A. (2018). Social and Cultural Geographies of Ageing. Mark W. Skinner, Gavin J. Andrews, Malcolm P. Cutchin (Eds.), Geographical Gerontology: Perspectives, Concepts, Approaches içinde (43-55). New York: Routledge.

Milligan, C., Wiles, J.L. (2010). Landscapes of Care. Progress in Human Geography, 34(6), $736-754$. doi: $10.1177 / 0309132510364556$

Moore, E., Rosenberg, M. W. (2001). Canada's Elderly Population: The Challenges of Diversity. The Canadian Geographer, 45(1), 145-150.

Newbold, K.B. (2008). Interprovincial Migration and Retirement Income Transfers among Canada's Older Population: 19962001. Environment and Planning A, 40(6), 1501-1516. doi: 10.1068/a39188

Nordstrom, C.K., Diez-Roux, A.V., Jackson, S.A., Gardin, J.M. (2004). The association of personal and neighbourhood socioeconomic indicators with subclinical cardiovascular disease in an elderly cohort. The cardiovascular health study. Social Science \& Medicine, 59(10), 2139-2147. doi: 10.1016/j.socscimed.2004.03.017 
Özgür, E.M. (1999). Türkiye Nüfusunun Yaş Yapısı. Ankara Üniversitesi Türkiye Coğrafyası Araştırma ve Uygulama Merkezi Dergisi, 7, 159-174.

Özgür, E.M. (2010). Türkiye'nin Yaşlanma Sürecine Coğrafi Bir Bakış. 1. Ulusal Nüfusbilim Kongresi, 9-10 Ekim 2010, Ankara.

Özgür, E.M. (2013). Türkiye Nüfusundaki Doğurganlık Düşüşü ve Yaşlanma Eğilimi. Dernekler Dergisi, 23 (2013/2), 30-35.

Özgür, E.M. (2016). Bir Alt Alan Olarak Nüfus Coğrafyasının Geçmişi, Bugünü ve Geleceği. Ege Coğrafya Dergisi 25(1), 136.

Peace, S., Holland, C., Kellaher, L. (2006). Environment and Identity in Later Life. Maidenhead, UK: Open University Press.

Peng, X. (2008). Demographic Shift, Population Ageing and Economic Growth in China: A Computable General Equilibrium Analysis. Pacific Economic Review, 13(5), 680-697. doi: 10.1111/j.1468-0106.2008.00428.x

Phillips, D., Siu, O.L., Yeh, A.G.O., Cheng, K.H.C. (2005). The Impacts of Dwelling Conditions on Older Persons' Psychological Well-Being in Hong Kong: The Mediating Role of Residential Satisfaction. Social Science and Medicine, 60(12), 2785-2797. doi: 10.1016/j.socscimed.2004.11.027

Pickle, L.W., Mungiole, M., Jones, G.K., White, A.A. (1996). Atlas of United States Mortality. Washington, DC: Center for Disease Control.

Pugh, J., Thien, D., Marres, N., et al. (2009). What Are the Consequences Of The 'Spatial Turn' For How We Understand Politics Today? A Proposed Research Agenda. Progress in Human Geography, 33(5), 579-586. doi: $10.1177 / 0309132508099795$

Reid, A., Harding, S. (2000). Trends in Regional Deprivation and Mortality Using the Longitudinal Study. Health Statistics Quarterly, 5, 17-25.

Rosenberg, M.W. (2014). Health geography I: Social Justice, Idealist Theory, Health and Health Care. Progress in Human Geography, 38(3), 466-475. doi:10.1177/0309132513498339

Rosenberg, M.J., Everitt, J. (2001). Planning for Aging Populations: Inside or Outside the Walls. Progress in Planning, 56(3), 119-168. doi: 10.1016/S0305-9006(01)00014-9

Rosenberg, M.W., Wilson, K. (2018). Population Geographies of Older People. Mark W. Skinner, Gavin J. Andrews, Malcolm P. Cutchin (Eds.), Geographical Gerontology: Perspectives, Concepts, Approaches içinde (56-67). New York: Routledge.

Rowles, G. (1978). Prisoners of Space? Exploring the Geographical Experience of Older People. Boulder, Colo: Westview Press.

Rowles, G.D. (1983). Place and personal identity in Old Age: Observations from Appalachia. Journal of Environmental Psychology, 3(4), 299-313.

Rowles, G.D. (1986). The Geography of Ageing and the Aged: Towards an Integrated Perspective. Progress in Human Geography, 10(4), 511-539. doi: 10.1177/030913258601000403

Rowles, G.D. (1993). Evolving Images of Place in Aging and 'Aging in Place'. Generations, 17(2), 65-70.

Rowles, G.D., Ravdal, H. (2002). Aging, Place, and Meaning in The Face of Changing Circumstances. Robert S. Weiss \& Scott A. Bass (Eds.), Challenges of The Third Age: Meaning and Purpose in Later Life içinde (81-114). New York: Oxford University Press.

Rowles, G.D., Watkins, J.F. (1993). Elderly Migration and Development in Small Communities. Growth \& Change, 24(4), 509-538.

Rubinstein, R. L. (1989). The Home Environments of Older People: A Description of the Psycho-Social Processes Linking Person to Place. Journal of Gerontology: Social Sciences, 44(2), 45-56.

Rubinstein, R.L. (1990) Personal Identity and Environmental Meaning in Later Life. Journal of Aging Studies, 4(2), 131-148.

Russ, T.C., Batty, G.D., Hearnshaw, G.F., Fenton, C., Starr, J.M. (2012). Geographical Variation in Dementia: Systematic Review with Meta-Analysis. International Journal of Epidemiology, 41(4), 1012-1032. doi: 10.1093/ije/dys103

Rudzitis, G. (1984). Geographical Research and Gerontology: An Overview. The Gerontologist, 24(1), 536-542. 
Scharf, T., Phillipson, C., Smith, A. (2005). Social Exclusion of Older People in Deprived Urban Communities of England. European Journal of Aging, 2(2), 76-87. doi:10.1007/x10433-005-0025-6

Shelton, N., Grundy, E. (2000). Proximity of Adult Children to Their Parents in Great Britain. International Journal of Population Geography, 6(3), 181-195. doi: 10.1002/1099-1220(200005/06)6:3<181::AID-IJPG181>3.0.CO;2-U

Skinner, M.W. (2008). Voluntarism and long-term care in the countryside: the paradox of a threadbare sector. The Canadian Geographer, 52, 188-203. doi: 10.1111/j.1541-0064.2008.00208.x

Skinner, M.W., Joseph, A.E. (2007). The Evolving Role of Voluntarism in Ageing Rural Communities. New Zealand Geographer, 63(2), 119-129. doi: 10.1111/j.1745-7939.2007.00096.x

Skinner, M.W., Rosenberg, M.W. (2005). Co-opting Voluntarism? Exploring the Implications of Long-term Care Reform for the Nonprofit Sector in Ontario. Environment and Planning C: Government and Policy, 23(1), 101-121. doi: $10.1068 / \mathrm{c} 0434$

Skinner, M.W., Winterton, R. (2018). Rural Ageing: Contested Spaces, Dynamic Places. Mark W. Skinner, Gavin J. Andrews, Malcolm P. Cutchin (Eds.), Geographical Gerontology: Perspectives, Concepts, Approaches içinde (136-148). New York: Routledge.

Skinner, M. W., Cloutier, D., Andrews, G. J. (2015). Geographies of Ageing: Progress and Possibilities after Two Decades of Change. Progress in Human Geography, 39(6), 776-799. doi: 10.1177/0309132514558444

Skinner, M.W., Andrews, G.J., Cutchin, M.P. (2018). Introducing Geographical Gerontology. Mark W. Skinner, Gavin J. Andrews, Malcolm P. Cutchin (Eds.), Geographical Gerontology: Perspectives, Concepts, Approaches içinde (1-10). New York: Routledge.

Skinner, M.W., Rosenberg, M.W., Lowell, S.A., Dunn, J.R., Everitt, J.C., Hanlon, N., Rathwell, T.A. (2008). Services for Seniors in Small Town Canada: The Paradox of Community. Canadian Journal of Nursing Research, 40(1), 80-101.

Smith, G. (1998a). Geographic Separation and Patterns of Social Interaction between Residents of Senior Citizen Apartment Buildings and Their Adult Children. The Canadian Geographer, 42(2), 145-158. doi:10.1111/j.15410064.1998.tb01561.x

Smith, G. (1998b). Residential Separation and Patterns of Interaction between Elderly Parents and Their Adult Children. Progress in Human Geography, 22(3), 368-384. doi: 10.1191/030913298673626843

Smith, A., Sim, J., Scharf, T., Phillipson, C. (2004). Determinants of Quality of Life amongst Older People in Deprived Neighbourhoods. Ageing \& Society, 24(5), 793-814. doi: 10.1017/S0144686X04002569

Soja, E.W. (2009). Taking Space Personally. Barney Warf ve Santa Arias (Eds.), The Spatial Turn: Interdisciplinary Perspectives içinde (11-35). New York: Routledge.

Stephens, C., Breheny, M., Mansvelt, J. (2015). Volunteering as Reciprocity: Beneficial and Harmful Effects of Social Policies to Encourage Contribution in Older Age. Journal of Aging Studies, 33, 22-27. doi: 10.1016/j.jaging.2015.02.003

Sugihara, S., Evans, G.W. (2000). Place Attachment and Social Support at Continuing Care Retirement Communities. Environment and Behavior, 32(3), 400-409. doi: 10.1177/00139160021972586

Suh, G.H., Shah, A. (2001). A Review of the Epidemiological Transition in Dementia-Cross-national Comparisons of the Indices Related to Alzheimer's Disease and Vascular Dementia. Acta Psychiatrica Scandinavica, 104(1), 4-11. doi: 10.1034/j.1600-0447.2001.00210.x

Sunil, T.S., Rojas, V., Bradley, D.E. (2007). United States' International Retirement Migration: The Reasons for Retiring to the Environs of Lake Chapala, Mexico. Ageing and Society 27, 489-510. doi: 10.1017/S0144686X07005934

Südaş, İ. (2005). Türkiye'ye Yönelik Göçler ve Türkiye'de Yaşayan Yabancılar: Alanya Örneği. İzmir: Ege Üniversitesi Sosyal Bilimler Enstitüsü Yayınlanmamış YL Tezi. https://tez.yok.gov.tr/UlusalTezMerkezi/tezSorguSonucYeni.jsp adresinden edinilmiştir.

Südaş, İ. (2012). Avrupa Ülkelerinden Türkiye'nin Batı Klyılarına Yönelik Göçler: Marmaris, Kuşadası ve Ayvalık İlçelerinde Karşılaştırmalı Bir Araştırma. İzmir: Ege Üniversitesi Sosyal Bilimler Enstitüsü Yayınlanmamış DR Tezi. https://tez.yok.gov.tr/UlusalTezMerkezi/tezSorguSonucYeni.jsp adresinden edinilmiştir.

Sylvestre, G. (1999). The Geography of Aging: A Geographical Contribution to Gerontology. Rohanda Koster (Ed.), Prairie Perspectives: Geographical Essays içinde (Vol. 2, 214-224). Saskatoon: University of Winnipeg. 
Şenol, E. (2016). Giresun Ilinde Mevsimlik Yaşlı Göçleri. TÜCAUM Uluslararası Coğrafya Sempozyumu 13-14 Ekim 2016 Bildiriler Kitabı içinde (568-569). Ankara.

Şenol, E., Saraçoğlu, H. (2012). Tokat Kentinde Yaşlı Nüfusun Mekânsal Dağılışı ve Kent Içi Arazi Kullanımının Yaşlı Nüfusun Yaşam Kalitesine Etkileri. Ali Açıkel, Samettin Başol, A.Osman Solmaz ve Murat Hanilçe (Eds.), Tokat Seтроzуити (1-3 Kasım 2012) Bildiriler Kitabı içinde (97-116). Tokat.

Türkiye İstatistik Kurumu-TÜİK (2015). İstatistiklerle Yaşlılar 2014. Ankara: TÜİK.

United Nations-UN (2002a). World Population Ageing 1950-2050. UN Population Division, DESA, Sales No. E.02.XIII.3.

United Nations (2002b). Report of the Second World Assembly on Ageing, Madrid, 8-12 April 2002. United Nations Publication Sales No. E.02.IV.4.

United Nations (2004). Policy Responses to Population Decline and Ageing. Population Bulletin of the United Nations, Special Issue Nos. 44/45. Sales No. E.02.XIII.4.

United Nations-UN (2007a). World Population Ageing 2007. New York: United Nations, Department of Economic and Social Affairs, http://www.un.org/esa/population/publications/WPA2007/wpp2007.htm

United Nations-UN (2007b). Development in an Ageing World. World Economic and Social Survey 2007E/2007/50/Rev.1 ST/ESA/314. New York: UN.

United Nations-UN (2012). Ageing in the Twenty-First Century: A Celebration and A Challenge. New York: United Nations Population Fund-UNFPA.

United Nations-UN (2017). World Population Prospects: The 2017 Revision. Department of Economic and Social Affairs, Population Division, DVD Edition.

Ünal, Ç. (2013). Türkiye Nüfus Yapısındaki Değişimler ve Demografik Fırsatlar. Coğrafyacılar Derneği Yıllık Kongresi 2013. İstanbul.

Ünal, Ç. (2015). Türkiye Nüfusunun Yaşlanma Endeksi ve Potansiyel Destek Oranlarının Dağılımı. Hasan Ali Yücel Eğitim Fakültesi Dergisi, 12-1(23), 235-249.

Van der Pers, M., Mulder, C.H., Steverink, N. (2015). Geographic proximity of adult children and the well-being of older persons. Research on Aging, 37(5), 524-551. doi: 10.1177/0164027514545482

Wahl, H.W., Wiesman, G.D. (2003). Environmental Gerontology at the Beginning of the New Millennium: Reflections on Its Historical, Empirical, and Theoretical Development. The Gerontologist, 43(5), 616-627.

Walter-Ginzburg, A., T. Blumstein, T., Guralnik, J.M. (2004). The Israeli Kibbutz as a Venue for Reduced Disability in Old Age: Lessons from the Cross-Sectional and Longitudinal Aging Study (CALAS). Social Science \& Medicine, 59(2), 389-403. doi: 10.1016/j.socscimed.2003.10.026

Warf, B., Arias, S. (2009). Introduction: The Reinsertion of Space into the Social Sciences and Humanities. Barney Warf ve Santa Arias (Eds.), The Spatial Turn: Interdisciplinary Perspectives içinde (1-10). New York: Routledge.

Warnes, A.M. (1981). Towards a Geographical Contribution to Gerontology. Progress in Human Geography, 5(3), $317-341$.

Warnes, A.M. (Ed.) (1982). Geographical Perspectives on the Elderly. London: John Wiley.

Warnes, A.M. (1990). Geographical Questions in Gerontology: Needed Directions for Research. Progress in Human Geography, 14(1), 24-56. doi: 10.1177/030913259001400103

Warnes, A.M. (1999). UK and Western European Late-age Morality: Trends in Cause-Specific Death Rates, 1960-1990. Health and Place, 5(1), 111-118.

Warnes, A.M., Williams, A. (2006). Older Migrants in Europe: A New Focus for Migration Studies. Journal of Ethnic and Migration Studies, 32(8), 1257-1281. doi: 10.1080/13691830600927617

Warnes, T. (2009). International Retirement Migration. Peter Uhlenberg (Ed.) International Handbook of Population Aging, International Handbooks of Population (Vol. 1, 341-363). Dordrecht: Springer.

Wiles, J. (2003a). Daily Geographies of Caregivers: Mobility, Routine, Scale. Social Science \& Medicine, 57, 1307-1325. doi: $10.1016 / \mathrm{S} 0277-9536(02) 00508-7$ 
Wiles, J. (2003b). Informal Caregivers' Experiences of Formal Support in a Changing Context. Health and Social Care in the Community, 11, 189-207. doi: 10.1046/j.1365-2524.2003.00419.x

Wiles, J. (2005). Conceptualizing Place in the Care of Older People: The Contributions of Geographical Gerontology. International Journal of Older People Nursing, 14(2), 100-108. doi: 10.1111/j.1365-2702.2005.01281.x

Wiles, J.L. (2011). Reflections on Being a Recipient of Care: Vexing the Concept of Vulnerability. Social and Cultural Geography, 12(6), 573-588. doi: 10.1080/14649365.2011.601237

Wiles, J.L. (2018). Health Geographies of Ageing. Mark W. Skinner, Gavin J. Andrews, Malcolm P. Cutchin (Eds.), Geographical Gerontology: Perspectives, Concepts, Approaches içinde (31-42). New York: Routledge.

Wiles, J. L., Jayasinha, R. (2013). Care for Place: The Contributions Older People Make to Their Communities. Journal of Aging Studies, 27(2), 93-101. doi:10.1016/j.jaging.2012.12.001

Wimo, A., Winblad, B., Aguero-Torres, H., von Strauss, E. (2003). The Magnitude of Dementia Occurrence in the World. Alzheimer Disease and Associated Disorders, 17, 63-67.

Wisensale, S. K. (2003). Global Aging and Intergenerational Equity. Journal of Intergenerational Relationships, 1(1), 29-47. doi: 10.1300/J194v01n01_05

Wisensale, S. K. (2006). Aging Societies and Intergenerational Equity Issues. Journal of Feminist Family Therapy, 17(3), 79103. doi: 10.1300/J086v17n03_05

Wolf, D., Ballal, S. S. (2006). Family Support for Older People in an Era of Demographic Change and Policy Constraints. Ageing and Society, 26(5), 693-706. doi:10.1017/S0144686X06005289

World Health Organization-WHO (2002a). Life Tables for 191 Countries: World Mortality in 2000 file://C:/Users/Pc/Downloads/9241562048-eng-fre-spa-HR.pdf

World Health Organization (WHO) (2002b). Active Aging: A Policy Framework. Geneva: WHO.

World Health Organization-WHO (2007). Global Age-friendly Cities: A Guide. Geneva: WHO.

World Health Organization-WHO (2008). Atlas of Health in Europe. Copenhagen: WHO.

World Health Organization (2015). World Report on Ageing and Health. Geneva: WHO.

World Health Organization-WHO (2017). Age-friendly Environments in Europe: A Handbook of Domains for Policy Action. Copenhagen: WHO.

World Health Organization-WHO (2018). World Health Statistics 2018: Monitoring Health for the SDGs, Sustainable Development Goals. Geneva: WHO.

Yakar, M. (2012). İç ve Dış Göçlerin Kırsalda Nüfusun Yaş Yapısına Etkisi: Emirdağ İlçesi Örneği. Coğrafi Bilimler Dergisi, 10(2), 129-149.

Yakar, M. (2014). Türkiye'de Ilçelere Göre Medyan Yaş Dağılımının Mekânsal ve Istatistiksel Analizi. Turkish Studies, 9(11), 559-591. doi: 10.7827/TurkishStudies.7447

Yakar, M. (2015). "Hem yaşlı, hem yalnız": Türkiye'de Yaşlı Dul Nüfusun Gelişimi ve Mekânsal Dağılımı. Hacettepe Üniversitesi Nüfus Etütleri Enstitüsü, IV. Nüfusbilim Konferansı (5-6 Kasım 2015), Ankara.

Yakar, M. (2017). "From Old Age to Advanced Agedness": The Spatial Distribution and Growth of Population Ageing In Turkey. International Symposium on GIS Applications in Geography and Geosciences (ISGGG), October 18-21, Çanakkale, Turkey.

Yakar, M. (2018). Yaşlanma ve Yaşl11ığa Coğrafi Bir Yaklaşım. Nurettin Özgen (Ed.), Sosyal Coğrafya içinde (349-382). Ankara: Pegem Akademi.

Yılmaz, M. (2016). Türkiye'nin Değişen Nüfus Yapısı: Nedenler, Değişim, Sonuçlar ve Gelecek. İstanbul: Çantay. 